\title{
The effect of traffic on the movement of eastern chipmunks (Tamias striatus)
}

By

\section{Adam T. Ford}

\author{
A thesis submitted to \\ the Faculty of Graduate Studies and Research \\ in partial fulfilment of \\ the requirements for the degree of
}

\section{Masters of Science}

\author{
Department of Biology \\ Carleton University \\ Ottawa, Ontario \\ May, 2006 \\ (C), Adam T. Ford
}




$\begin{array}{ll}\begin{array}{l}\text { Library and } \\ \text { Archives Canada }\end{array} & \begin{array}{l}\text { Bibliothèque et } \\ \text { Archives Canada }\end{array} \\ \begin{array}{l}\text { Published Heritage } \\ \text { Branch }\end{array} & \begin{array}{l}\text { Direction du } \\ \text { Patrimoine de l'édition }\end{array} \\ \begin{array}{l}\text { 395 Wellington Street } \\ \text { Ottawa ON K1A 0N4 }\end{array} & \begin{array}{l}\text { 395, rue Wellington } \\ \text { Ottana ON K1A ON4 } \\ \text { Canada Oa }\end{array}\end{array}$

Your file Votre référence ISBN: 978-0-494-16495-2 Ourfile Notre référence ISBN: 978-0-494-16495-2

NOTICE:

The author has granted a nonexclusive license allowing Library and Archives Canada to reproduce, publish, archive, preserve, conserve, communicate to the public by telecommunication or on the Internet, loan, distribute and sell theses worldwide, for commercial or noncommercial purposes, in microform, paper, electronic and/or any other formats.

The author retains copyright ownership and moral rights in this thesis. Neither the thesis nor substantial extracts from it may be printed or otherwise reproduced without the author's permission.
AVIS:

L'auteur a accordé une licence non exclusive permettant à la Bibliothèque et Archives Canada de reproduire, publier, archiver, sauvegarder, conserver, transmettre au public par télécommunication ou par l'Internet, prêter, distribuer et vendre des thèses partout dans le monde, à des fins commerciales ou autres, sur support microforme, papier, électronique et/ou autres formats.

L'auteur conserve la propriété du droit d'auteur et des droits moraux qui protège cette thèse. $\mathrm{Ni}$ la thèse ni des extraits substantiels de celle-ci ne doivent être imprimés ou autrement reproduits sans son autorisation.
In compliance with the Canadian

Privacy Act some supporting forms may have been removed from this thesis.

While these forms may be included in the document page count, their removal does not represent any loss of content from the thesis.
Conformément à la loi canadienne sur la protection de la vie privée, quelques formulaires secondaires ont été enlevés de cette thèse.

Bien que ces formulaires aient inclus dans la pagination, il n'y aura aucun contenu manquant. 


\section{ABstract}

Previous studies suggest that eastern chipmunks (Tamias striatus) avoid roads, but it is unclear whether vehicle traffic plays a role in this avoidance. The purpose of this study was to determine whether road avoidance in chipmunks increases with increasing traffic. We also tested whether chipmunks display anti-predator responses, such as tree climbing and use of coarse woody debris, in response to road traffic. We tracked the movements of 68 chipmunks released near roads with widely varying traffic amounts. Our results confirm that chipmunks avoid roads, but we found no evidence suggesting this response is caused by traffic. We also found no evidence suggesting that chipmunks display antipredator responses to road traffic. Chipmunks need to disperse between remnant forest patches in order to maintain regional population persistence. Our results clearly show that roads inhibit chipmunk movement; therefore, we predict that the primary effect of roads on chipmunk populations is due to population subdivision. 


\section{ACKNOWLEDGEMENTS}

I came to Carleton University as a curious naturalist who wanted to learn more about the world around him; my goal was to leave with an ability to ask better questions and to provide clear responses when questions are asked of me. No one has been more instrumental in seeing me reach that goal than my supervisor, Lenore Fahrig. It has been a real pleasure to work under your guidance and I certainly could not have asked for a more productive and enjoyable two years than the time I spent in your research lab. Thank you for giving me this opportunity to grow as a person and into a scientist.

I would also like to thank my committee members, Tom Sherratt and Gabriel Blouin-Demers. Both of these gentlemen have endured more committee meetings than should be asked of them, and I thank them for their patience and advice. Kringen Henein has acted as a surrogate committee member by providing me with invaluable knowledge of small mammals, not to mention the best trap bait recipe ever invented. A big thanks to all the folks who helped fund this project as well, namely NSERC and the Department of Biology. I would also like to recognize the contribution of the many private landowners involved in this research; without access to their property this study would have been far more difficult.

I had one of the best field crews a graduate student could hope for, with all-star munk-master Alex MacIntosh taking the brunt of pilot projects, mosquitoes, and vegetation surveys. Thanks to Allison Callahan and Elizabeth Ross for their help with the 'munking and to Tyler Wheeldon, Ami Kingdon and Tiffany Johnson for their efforts in the field and the lab. A big thanks to Christy Nieman, Denis Latremouille and Wayne Richardson for their GIS script, which they not only made as part of their own 
coursework, but updated versions for me as the months went on well past the due date for their assignment. Certainly the community of researchers in the GLEL have made important contributions to this work in so many different ways. Thank you to Dave Omond who helped me right from the start in preparing for the field season. Dan Bert was always there to support me, without hesitation, through the various equipment and computer challenges I faced. Thanks to my co-conspirators in this oikos: Trina, Leif, Amanda, Felix, Sarah and Mark. You have not only provided me with valuable advice and support, you have also kept me distracted when I needed it and Mike's Place was all the more profitable as a result.

Thank you to my family: Mom, Dad and Rachel. From long ago you guys have supported all of my endeavours and instilled in me the confidence I needed to live my dreams. Thanks to my besties Matt, Matt and Andy. You guys were there for me in the early days and never said no to a little field work when I needed help (even though I may end up studying squirrels by the end of the day, what?). You guys are also part of that small group of people in this world that did not laugh at me when I told them I was studying chipmunks. At least you did not laugh for very long.

Lastly, but most especially, I would like to thank Sarada for all of her support during the past two years. I really cannot describe how much your support means to me, all I can say is that you have put up with a lot of late nights, a lot of 'munk talk and a lot of my stress but never have you questioned my dream of doing this work. More than that, you have enabled me to keep an especially positive perspective on my life while I was neck-deep in fermenting peanut butter balls: thanks. 


\title{
DEDICATION
}

This thesis is dedicated to travelling individuals everywhere, especially the sciurid rodents of Ottawa. May you always find a way to cross the barriers in your path.

They ran on and crept through the hedge. Hazel looked down the road in astonishment. For a moment he thought that he was looking at another riverblack, smooth and straight between its banks. Then he saw the gravel embedded in the tar and watched a spider running over the surface.

'But that's not natural,' he said, sniffing the strange, strong smells of tar and oil. 'What is it? How did it come there?'

'It's a [hu]man-thing, 'said Bigwig. "they put that stuff there and then the hrududil run on it -faster than we can; and what else can run faster than we?'

'It's dangerous then? They can catch us?'

'No, that's what's so odd. They don't take any notice of us at all. I'll show you, if you like.'

\author{
Richard Adams \\ Watership Down p.58-59 \\ Penguin Books Ltd, \\ Harmondsworth, England
}




\section{TABLE OF CONTENTS}



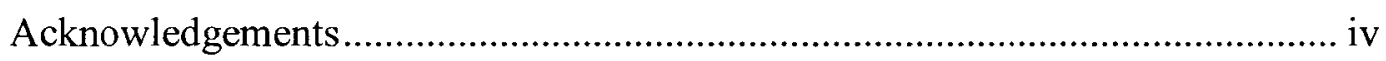

Dedication ...................................................................................... vi

Table of Contents .............................................................................. vii

List of Tables ........................................................................................... vii

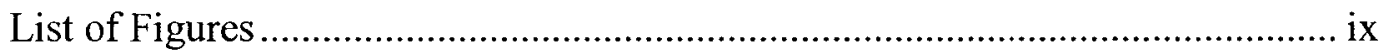

List of Appendices ................................................................................. xi

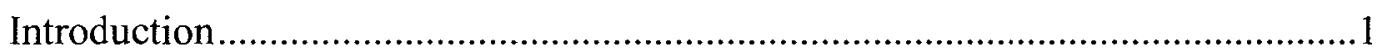

Life History of the Eastern Chipmunk ...................................................

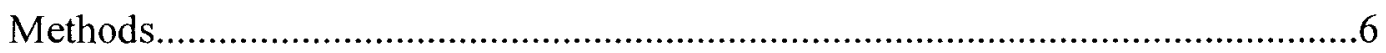





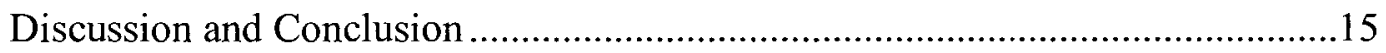

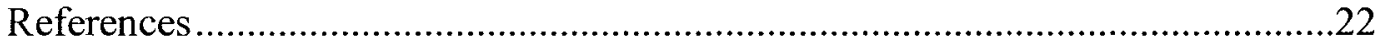




\section{LIST OF TABLES}

Table 1. Site data

Table 2. Summary statistics for the exit direction analysis. Vehicle refers to releases performed when a vehicle was passing through the site

Table 3. ANOVA table for the effect of traffic on the mean turning angle when chipmunks were moving towards the road

Table 4. ANOVA table for minimum distance from the road. Data $(n=10)$ from one site (Site A) were excluded from this analysis because this site had a verge width twice the typical verge width of the other sites [Table 1]

Table 5. ANOVA table for median distance from the road. Data $(n=10)$ from one site (Site A) were excluded from this analysis because this site had a verge width twice the typical verge width of the other sites [Table 1]

Table 6. ANOVA table for proportion of chipmunks that climbed trees at each site. Mean traffic is the mean of the log normal 60 minute traffic count from each release at a given site

Table 7. ANOVA table for the mean use of coarse woody debris by chipmunks. Mean traffic is the mean of the log normal 60 minute traffic count from each release at a given site 


\section{LIST OF FIGURES}

Figure 1. Mechanism for releasing individual chipmunks. The left photo shows the tripod and release device as it appeared prior to release of an animal. The right photo shows the false roof after the outer box has been removed

Figure 2. Graphical representation of all pathways greater than $40 \mathrm{~m}$ in length. Solid lines are pathways at low traffic sites and the double-dashed line are pathways from high traffic sites. The dark gray area represents the verge, the light gray area is the forest and the black area is the road surface. The approximate location of the release point is indicated by the black star. Each grid cell represents $2 \mathrm{~m}^{2}$. The mean verge width of Sites B-F was used for this figure. Site A was excluded because its verge width was almost twice as large as the verge width of the other sites (Table 1).

Figure 3. Histograms of exit direction bearings. Bars represent a width of $12^{\circ}$, concentric rings indicate a frequency of 2 pathways. Numbers outside of the circle are the bearings of the cardinal directions with $0^{\circ}$ indicating movement directly towards the road. The black vector is the mean direction and the arc outside of the circle is the $95 \%$ confidence interval. Vehicle refers to releases performed when there was a vehicle passing through the site.

Figure 4. Effect of traffic amount on the mean turning angle when chipmunks were heading towards the road $\left(315^{\circ}\right.$ to $\left.45^{\circ}\right)$. Adjusted $R^{2}=0.084$ for the model.

Figure 5. Effect of traffic amount on minimum distance from the road. Site A was excluded from this analysis; see text for explanation. Adjusted $\mathrm{R}^{2}<0.01$ for the model.

Figure 6. Effect of traffic amount on median distance from the road. Site A was excluded from this analysis; see text for explanation. Adjusted $R^{2}<0.01$ for the model 
Figure 7. Relationship between use of trees by chipmunks and traffic amount at six test sites. Residuals from the percent of chipmunks climbing trees regressed on tree density were plotted against traffic amount, to illustrate the effect of traffic amount when tree dispersion is controlled for.

Adjusted $\mathrm{R}^{2}=0.464$ for the model.

Figure 8. Relationship between use of coarse woody debris and traffic amount at six test sites. Residuals from CWD amount at each site regressed on the mean proportion of each pathway that ran along CWD, to illustrate the effect of traffic amount when CWD amount is controlled for. Adjusted $\mathrm{R}^{2}=0.884$ for the model. 


\section{LIST OF APPENDICES}

Appendix A. Number of chipmunks contributed by each trapping site to each release site and distances between all pairs of sites.

Appendix B. Coordinates of trapping sites, given in MTM Zone 9 Projection....38

Appendix C. Coordinates of release sites, given in MTM Zone 9 Projection.......38

Appendix D. Summary data of chipmunks used in this study. All references to dates occurred during 2005. Shaded rows indicate data excluded from regression analyses. Data are available in Appendix F. Car refers to the passing of a vehicle in the site when the animal was released with $Y$ indicating the presence of a vehicle. The mean turning angle is only calculated for sequential pathway segments when the first segment was heading towards the road and the second segment deviated more than $20^{\circ}$ from the previous bearing.

Appendix E. Pathway maps from each release. The italicized number to the right of the figure corresponds to the Animal ID in Appendix D. The light grey area represents the forest, the dark grey area represents the roadside verge and the black area represents a portion of the road edge starting at the verge/road edge. The entire width of the road surface is not represented in these maps. The grid cells are $2 \mathrm{~m}^{2}$. Pathways are represented by the irregular black line, unless the pathway ventured onto the road surface in which case the pathway is white. The release location is at the same coordinate at each site, $4 \mathrm{~m}$ from the forest/verge edge.

Appendix F. Compact disc with the pathway raw data (distance, zeroed bearing, substrate type and calculated coordinates). Files are grouped by site and listed by release date. The column heading "Habitat" refers to substrate type: F: forest floor, L: coarse woody debris and A: arboreal travel.

Tables 1 to 7 and Appendices $\mathrm{A}$ to $\mathrm{E}$ are also included. [enclosed] 


\section{Introduction}

Road network density and the number of vehicles on the road are increasing in many jurisdictions such that conservation efforts are becoming more involved with the interaction between roads and wildlife (Forman et al. 2003). The effect of roads on wildlife populations includes the loss and fragmentation of habitat as well as mortality associated with wildlife-vehicle collisions (e.g. Dodd et al. 2004; Findlay \& Bourdages 2000; Fahrig et al. 1995; Forman et al. 2003; Saeki \& McDonald 2004).

The magnitude of a road's effect on a given population depends on the species' response to road variables, such as road width and traffic amount (Mader 1984; Forman et al. 2003). Jaeger et al. (2005) modelled the effects of road size and traffic amount on population persistence and predicted that traffic amount has the greatest effect on the magnitude of the road impact. Traffic affects wildlife populations by increasing mortality (Caro et al. 2000; Clarke et al. 1998; Clevenger 2003; McClure 1951; Oxley et al. 1974) and road avoidance (Richardson et al. 1997). Road avoidance is any response by individual animals that reduces movement onto the road surface.

Jaeger et al. (2005) predict that the effect of traffic on mortality is negligible if animals avoid roads due to traffic or if they avoid the road surface per se. At the same time, as road avoidance increases the effect of the road on habitat fragmentation (causing resource inaccessibility and/or population subdivision) increases. If a species has a weak response to traffic and does not avoid the road surface then mortality increases with traffic amount (e.g. Carr \& Fahrig 2001).

Several studies have examined the effect of roads on the movement of small mammals and found that many species exhibit some degree of road aversion (e.g. Burnett 
1992; Clark et al. 2001; Conrey \& Mills 2001; Mader 1984; McDonald \& St. Clair 2004a; Rondini \& Doncaster 2002; Swihart \& Slade 1984). It is unclear from these studies how traffic interacts with road avoidance because of the confounding effects of road width and traffic amount in these studies. To our knowledge only two studies have directly examined the effect of traffic amount on small mammal movement. Richardson et al. (1997) found that two species of vole had a significantly higher rate of road crossing at low traffic sites ( $<60$ vehicles per hour) than at high traffic sites $(>250$ vehicles per hour). McGregor (2004) found a slight effect $(\mathrm{p}=0.095)$ of traffic amount on white-footed mouse (Peromyscus leucopus) movement across roads; she argued that small mammal road avoidance is primarily due to road surface avoidance.

Most studies on small mammal road avoidance, including Richardson et al. (1997) and McGregor (2004), use capture-mark-recapture (CMR) techniques with trapping grids on both sides of a road to monitor the movement of marked individuals. Movement is either spontaneous or induced through homing by translocating animals across the road. Road avoidance is defined in these studies as a significantly lower frequency of recaptures between grids on opposite sides of the road, relative to the frequency of recaptures of equivalent distance on one side of the road only.

Results of CMR studies are difficult to interpret when attempting to address questions of movement near roads for at least three reasons. First, CMR methods are based on a discrete, often categorical, representation of space. With this coarse-grained approach there is no way to determine how animals moved between recaptures (Clark $e t$ al. 2001). For instance, animals may move onto the road surface and then turn back towards roadside habitat as a vehicle approaches (Andrews \& Gibbons 2005). This 
pattern of movement would suggest that animals can avoid individual vehicles. Animals may also move away from the road while travelling within roadside habitat due to avoidance of vehicle emissions such as noise or pollutants. Both of these types of road avoidance would increase with traffic but have different predicted effects on population persistence (Jaeger et al. 2005); however, using the frequency of road crossings as a measure of avoidance would not distinguish these two responses in the CMR approach. Second, many translocation CMR studies do not attempt to standardize, across animals, the motivation to cross the road (but see McDonald \& St. Clair 2004b). For instance, territorial individuals may have a stronger motivation to return to the initial capture location than dispersing individuals (Kozel \& Fleharty 1979). Third, some species of small mammals use roads to define the boundaries of their home range (Burnett 1992; Mader 1984; Swihart \& Slade 1984). CMR studies that depend on spontaneous movement of individuals outside the home range may confound road avoidance behaviour with avoidance of conspecific home ranges or territorial boundaries.

Several studies have suggested that chipmunks avoid roads. Oxley et al. (1974) found that chipmunks rarely crossed paved roads but frequently crossed low traffic, gravel roads. Conrey and Mills (2001) found that two species of chipmunks (Tamias amoenus and T. ruficaudus) were three times as likely to move adjacent to, rather than across, two-lane highways and never crossed four-lane highways. McGregor (2004) also found that fewer chipmunks crossed roads than was expected, although it is not clear from her study whether this result was caused by road aversion per se, a reluctance to move out of the forest onto the roadside verge or due to traffic mortality. Getty (1981) found that individual chipmunks included a low traffic road within their home range. 
Together, these studies indicate that chipmunks most likely avoid roads, but they may be more averse to some roads than others. It is unclear from the literature how road variables, such as surface composition, width or traffic amount, affect road aversion.

The purpose of this study was to determine whether a forest dwelling small mammal species, the eastern chipmunk (Tamias striatus), avoids roads due to traffic. We did this by tracking movement paths of individual chipmunks released in unfamiliar terrain near roads with widely varying traffic amounts. We predicted three responses if chipmunks avoid roads because of traffic. First, the probability of crossing a road should decrease with increasing traffic amount. Second, the size of the turns in chipmunk pathways should increase with traffic amount. Third, if chipmunks avoid the road because of traffic emissions, such as noise or pollutants, then animals will stay farther away from the road as traffic increases (Forman et al. 2003).

Studies on amphibians (Mazerolle et al. 2005) and snakes (Andrews \& Gibbons 2005) suggest that animals respond similarly to moving vehicles and predators, although this response may not necessarily direct the animal away from the road (Andrews \& Gibbons 2005). Chipmunks have been known to flee up trees when pursued by predators in unfamiliar habitat (Clarke et al. 1993) and to increase their use of coarse woody debris for travel in poor quality habitat (Zollner \& Crane 2003). We used two responses to test the hypothesis that chipmunks respond to vehicles as predators: the number of chipmunks that ascended trees and the use of coarse woody debris for travel by individuals. If chipmunks respond to vehicles as predators, we predicted that as traffic amount increases both the frequency of individuals that climb trees and the use of coarse woody debris should increase. 


\section{Life history of the eastern chipmunk}

The eastern chipmunk was chosen for this study because they are numerous in the study area, easily live-trapped, and their behavioural ecology is well documented. They are also listed as Specially Protected Mammal under the Ontario Fish and Wildlife Conservation Act (1997) through the Ontario Ministry of Natural Resources. Unless otherwise noted, the summary of life history presented here is based on Snyder (1982).

The eastern chipmunk ranges west to Lake Manitoba, east to Nova Scotia and from the southern tip of James Bay to northern Florida State. Preferred habitat throughout this range includes remnant deciduous forest, although tree-lined fencerows (Henderson et al. 1985), brushy areas, rock walls and wooded urban areas are also used. Chipmunks are diurnal and considered semi-fossorial as they burrow and hibernate below ground. They prefer to forage on the forest floor although they may make use of arboreal habitats for foraging. Preferred diet includes hard mast and invertebrates.

Mating takes place twice per year, between February and April and again in late June or early July. Gestation lasts approximately 30 days and litter size averages 4 young per mother. Young emerge from the burrow after 5 weeks and reach adult size within 3 months of birth. Mothers typically become intolerant of young within a few days of emergence leading to juvenile dispersal. Adult body mass is typically greater than $90 \mathrm{~g}$ and may reach more than $125 \mathrm{~g}$. Average life expectancy is 1.3 years with a maximum reported life span of 8 years.

Population densities have been reported up to 37.6 individuals/ha with recorded home ranges varying in size from 0.03 to 0.40 ha. Chipmunks are central place foragers and respond more strongly to microhabitat as distance from the burrow increases (Bowers 
1995; Clarke $e t$ al. 1993). Maximum recorded dispersal distance is $857 \mathrm{~m}$ and Loew (1999) found that mean dispersal distance for males is $345 \mathrm{~m}$ (maximum $>700 \mathrm{~m}$ ) and $85 \mathrm{~m}$ (maximum $350 \mathrm{~m}$ ) for females. Chipmunks have returned from translocations up to $500 \mathrm{~m}$ from their burrow.

Bowman and Fahrig (2002) found no effect of translocation distance on return rates of chipmunks translocated up to $250 \mathrm{~m}$ across open habitat (Bowman \& Fahrig 2002). Zollner (2000) found that chipmunks orient towards a forest edge from $120 \mathrm{~m}$ away when placed in a crop field, suggesting that chipmunks can perceive habitat from at least this distance. Chipmunks are also considered neophillic towards objects although they may explore new areas visually from a fixed position rather than moving within the new area (Wolfe 1969).

\section{Methods}

This study was conducted in the rural areas south and west of Ottawa (Ontario, Canada). This region is dominated by agricultural land use interspersed with small towns and remnant forest areas. Agricultural lands include hay, corn, soybean and other crop fields and are often bordered by tree-lined fencerows. Forests in this area typically consist of an overstory of Acer saccarum, Fraxinus americana, Tilia americana, Fagus grandifolia, Quercus macrocarpa, Tsuga canadensis, Pinus strobus, and Thuja sp.

Six test sites were selected for this study based on the following criteria: 1) a minimum $300 \mathrm{~m}$ of forest edge along both sides of the road, with no driveways, adjoining roads or housing; 2) mixed or deciduous dominant forest with closed canopy; 3) two-lane paved road surface. Three of the test sites were estimated to have low traffic and three 
were estimated to have high traffic (Table 1) based on preliminary surveys. The distance between forest edges on either side of the road ranged from 23 to $42 \mathrm{~m}$ (Table 1).

Trapping and handling procedures described here have been approved by the Carleton University Animal Care Committee and the Ontario Ministry of Natural Resources. Chipmunks were trapped from May 10 to August 9, 2005 from fencerows and forest patches using Sherman ${ }^{\mathrm{TM}}$ non-folding aluminium live-traps $(7.5 \mathrm{~cm} \times 9.0 \mathrm{~cm} \mathrm{x}$ $23.0 \mathrm{~cm}$ ) baited with a mixture of rolled oats, peanut butter and shelled peanuts. The trapping sites were located at least $5 \mathrm{~km}$ from the release sites. We chose this distance to minimize the likelihood that the animals would be familiar with the test site or would be homing towards the capture site while being tracked. A total of 7 sites, located no more than a 30minute walk from the nearest road, were used for trapping with each site ranging in contribution from 1- 26 individuals. Traps were opened in the morning (i.e. 7001100h) and checked and closed 4-6 hours later. Once trapped, chipmunks were sexed and weighed. Adults were defined as weighing more than $90 \mathrm{~g}$ and juveniles were less than $90 \mathrm{~g}$ (Loew 1999). Sex was determined in adults by examination of external reproductive organs. All pregnant or lactating females and young weighing less than $60 \mathrm{~g}$ were released at the point of capture. Chipmunks were held in a handling bag based on Koporowski (2002) during processing and anaesthesia was not used.

Chipmunks were fitted with a 3.0 or $4.5 \mathrm{~g}$ tracking spool (Imperial Thread Inc, Northbrook, IL), for juveniles and adults, respectively, with approximately $110 \mathrm{~m}$ of string for juvenile spools and $170 \mathrm{~m}$ of string for adult spools. Spool weights are less than $5 \%$ of the body mass of individuals for each age class. At each site approximately half of the trials were performed with adults and half with juveniles. 
Spools were inserted into a dark-coloured deflated balloon and glued to the back of the animal using VetBond ${ }^{\mathrm{TM}}$ surgical glue (3M Inc, St. Paul, MN), based on the procedure described in Zollner (2000). Chipmunks were transferred to test sites in an opaque, wooden box $(15.0 \mathrm{~cm} \times 30.5 \mathrm{~cm} \times 30.5 \mathrm{~cm})$, which was placed in the back of a climate controlled research vehicle for no more than 1.5 hours (Figure 1). There was no talking in the research vehicle while animals were being transported to the test site. Only one animal was released at a given test site per day.

Each animal was released in the following manner: first, the box containing the chipmunk was placed at the release point, which was at the same location at each site, $4 \mathrm{~m}$ from the forest/verge edge in the forest; second, the loose end of the tracking string was tied to a marker stake; third, a $1.5 \mathrm{~m}$ tall tripod was set up over the release box and one end of a $40 \mathrm{~m}$ string was fed through a pulley at the top of the tripod and attached to the lid of the box; lastly, one researcher walked parallel to the road for $40 \mathrm{~m}$, alternating the direction from the release box for sequential releases at each site and, after waiting quietly for 5minutes, the other end of the $40 \mathrm{~m}$ string was pulled, lifting the lid of the box. The box contained a false roof to provide the animal with a sense of security after the lid was removed and was designed to allow the animal to exit in any direction (Figure 1).

Half of all releases at each site were performed when a vehicle was passing by the release device and half were performed when no vehicle was passing by the site as the box was opened; however, at one site 10 of 13 releases were performed while a vehicle was passing due to an exceptionally high traffic amount (Table 1: Site A).

All releases were time stamped on a digital audio recorder (Panasonic RR-US360, Matsushita Electric, Japan) using hand-held radios (Cobra Electronics Corporation, 
Chicago, IL). The audio recorder was placed along side the road in the grassy verge and recorded traffic amount for 60 minutes following the release. Volume signatures were used to estimate traffic amount using software included with the recorder. Preliminary tests revealed that counting volume signatures using the software was as accurate as visual counting, except at very high traffic volumes ( $>700$ vehicles per hour), where sounds from one vehicle start overlapping with sounds from other vehicles. Therefore, some traffic amounts reported here may underestimate actual traffic during the study.

After at least 60 minutes, we returned to the release point to gather the box and tripod but we did not gather the string used to open the box until the following day. Each entry to the site was made from directly in front of the release device and care was taken to be quiet and quick to minimize our impact on the animal. No chipmunks were observed or heard while we were gathering the equipment. The morning after the release we returned to the site and followed the string trail left by the chipmunk.

Pathways were measured using a measuring tape and compass (Zollner 2000). The distance and bearing were recorded for each section of the pathway that deviated more than $20^{\circ}$ from the previous bearing, when an animal climbed a tree or when the animal travelled along coarse woody debris. Tree climbs were defined as movement that was more than $0.5 \mathrm{~m}$ off the ground located along or up a tree. Following Zollner and Crane (2003), travel along coarse woody debris (CWD) included sections of the pathway when the tracking string was directly over CWD and running lengthwise relative to the orientation of the CWD. Pin flags were used to mark sequential points along the path. Pathway bearings were zeroed such that due north indicated movement directly towards the road from the release point. Once zeroed, each point along the pathway was converted 
to Cartesian coordinates using a customized script for ArcView GIS 3.2 (Environmental Systems Research Institute, Redlands CA). The origin of the coordinate grid coincides with the location of the release point.

Verge width was measured at each site by taking the distance from the road shoulder to the tree line (tree trunks) directly between the release site and the road. The point-centered quarter method was used to measure tree density. We measured the distance from the plot center to the nearest tree $(>10 \mathrm{~cm}$ diameter at breast height $)$ in each quarter. This distance was converted to an area for each quarter:

$$
D=\frac{p \cdot r^{2}}{4}
$$

where $r$ is the distance from the plot center to the nearest tree in the quarter in meters. The sum of $D$ (4 quarters per plot x 10 plots) for each site was used to define tree density in $\mathrm{m}^{2}$. Five plots were located along the forest edge spaced $40 \mathrm{~m}$ apart and five plots were located $50 \mathrm{~m}$ into the forest interior at $40 \mathrm{~m}$ intervals running parallel to the forest edge. Percent CWD cover was measured by summing the total length of CWD along 10 transects per site, each $10 \mathrm{~m}$ long, and dividing this total by the total length of all transects $(100 \mathrm{~m})$. Transects were randomly oriented. CWD is defined as downed wood greater than $5 \mathrm{~cm}$ in diameter at the intersection with the transect line, and longer than $10 \mathrm{~cm}$. The same plots used to measure tree density were used to measure CWD amount.

\section{Statistical Analyses}

For the first prediction, that the probability of crossing the road decreases with traffic amount, we used a binary (i.e. cross/ no cross) logistic regression controlling for total length of pathway with log normal traffic amount as the predictor. 
For the second prediction, that the size of turns away from the road increases with increasing traffic amount, we analysed two responses: 1) the exit direction of each animal from the release device; 2) the mean size of the turning angle following movement segments when the animal was heading towards the road. To analyze the exit direction from the release device, releases were categorized based on a combination of the presence or absence of a vehicle passing by the site at the time of release and whether the release was performed at a high or low traffic site (Table 1), for a total of four groups. Each group was tested independently. Observed bearings were tested: 1) against a uniform distribution using Rao's Spacing Test; and 2), against an expected bearing of $180^{\circ}$ (indicating movement directly away from the road) with a V-Test. Significance $(\mathrm{p}<0.05)$ in the Rao's tests indicates that the bearings are not uniformly distributed. Significance $(p<0.05)$ in the V-Test indicates that bearings are concentrated near the specified mean. In the second analysis of this prediction we used turning angle size, defined as the mean turning angle between sequential pathway segments when the first segment was heading towards the road (i.e. $315-15^{\circ}$ ), as the response variable in a linear regression. We excluded any pathway segment found on the road surface from this analysis (see below). Log normal 60 minute traffic amount was used as the predictor. Analysis of circular data was performed using ORIANA v2.02c circular statistics program (Kovach Computing Services, Inc.).

For the third prediction, that the distance from the road to the animal increases with traffic amount, we performed two multiple regressions. For the first regression we used the minimum distance from the road for each movement path as the response variable and for the second regression we used median distance of the pathway from the 
road as the response variable. Independent variables in both analyses were total amount of pathway traced and traffic amount. Total amount of pathway traced was included in the model because the likelihood of an animal getting closer to the road should increase the farther the animal is tracked. For traffic amount we used the log normal 60 minute vehicle count following the release of the animal. Data $(n=10)$ from one site (Site A) were excluded from this analysis because this site had a verge width twice the typical verge width of the other sites (Table 1), which would greatly increase the distance from the road for any animals released at this site. This would give a spurious relationship with traffic amount because this site had the highest traffic amount.

Multiple regression analysis was used to test the prediction that the proportion of chipmunks at a site that climbed trees increased with traffic amount, measured as the mean log normal 60 minute traffic amount for the site. We controlled for the probability of encountering trees by including tree density as a predictor variable. Multiple regression was also used to test the prediction that use of CWD increased with traffic amount. The use of CWD by individuals at each site was calculated by summing the length of string that ran along CWD and dividing by the total length of the pathway for each individual. The response variable was the mean CWD used (across individuals) at each site. The amount of CWD at each site was included as predictor variable to control for the probability of encountering CWD. Five pathways ended prematurely because the tracking spool fell off the animal, which usually occurred shortly after release $(<50 \mathrm{~m}$ of pathway) and one other pathway we recorded was later found to contain measurement error and was subsequently removed. These pathways were excluded from all regression analyses. Multiple regressions were performed with the General Linear Model feature on 
SPSS v12.0.2 (SPSS Inc.).

We conducted a preliminary test to determine the durability of the tracking string when placed across a high traffic road. We laid five $30 \mathrm{~m}$ segments of tracking string from five different spools across the road at Site B for 20 hours starting at $1300 \mathrm{~h}$. This duration and time of day approximates the actual exposure of the string to traffic during the animal tracking component of this study. We found that two of five string segments laid across the road at Site B were severed. In both cases the breakage occurred $>2 \mathrm{~m}$ away from the paved surface boundary on the road surface itself. Thus, if an animal were to cross the road during our study but the string was severed by traffic by the time we returned to trace the pathway, then we would still likely find string on the road surface.

We conducted another preliminary test to determine how the position of the string is affected by passing vehicles. We manually played out five separate sections of string approximately $10 \mathrm{~m}$ in length starting in the roadside verge, arcing onto the road surface and then ending on the same side of the road as the start of the pathway about $2 \mathrm{~m}$ away from the starting point for each section. This pattern would simulate the pathway of a chipmunk that had moved onto the road surface and then turned back towards the forest, thereby mimicking road avoidance. We chose this pattern because we wanted to know if a potential absence of animal pathways on the road surface could be caused by passing vehicles blowing the string off the road, as opposed to actual road avoidance by chipmunks. We made direct observations of the string as vehicles drove near or over the simulated pathways and ended the observation period when the string appeared to stop moving as additional vehicles passed by. We found that portions of all five simulated pathways blew off the road surface due to wind and/or passing vehicles, although these 
segments never moved farther than the boundary between the pavement and the adjacent gravel shoulder of the road. Therefore, we will consider pathway segments found within $0.5 \mathrm{~m}$ of the paved road surface as movement on the road. Furthermore, we will exclude any pathway segments found on the road surface from analysis of the mean size of the turning angle.

\section{Results}

Figure 3 shows the pathways of each individual with respect to the forest and road edges, excluding those from Site A. Site A was excluded from this figure because the verge width at site $A$ was about twice the verge width at the other sites (Table 1), making it impossible to plot the pathways for Site A on the same figure as the pathways for the other sites. Among all sites, 25 individuals moved at least $2 \mathrm{~m}$ beyond the forest edge into the roadside verge and two of these pathways moved within $0.5 \mathrm{~m}$ of the road surface.

Only one animal was confirmed to have crossed a road during this study. One pathway terminated on the road surface, but we were unable to detect tracking string on the far side of the road so we could not determine whether the animal actually crossed. Therefore, an analysis of the effect of traffic amount on the probability of crossing the road could not be performed

We analysed the exit bearings of 68 chipmunks. The Rao's spacing test indicated a significantly non-uniform distribution of exit bearings at low traffic sites when a vehicle was passing by the site (Table 2; Figure 4c). Exit direction bearings at high traffic sites and at low traffic sites when no vehicle was passing by the site were not significantly different from random (Table 2). The results of the V-test indicate a 
significant clustering of exit direction bearings at $180^{\circ}$ (i.e. movement away from the road) for the releases at the low traffic sites when a vehicle was passing by the site (Figure 4c, Table 2) There also was a marginally significant clustering of exit direction bearings at $180^{\circ}$ for the low traffic releases when no vehicle was passing by the site and for high traffic releases when a vehicle was passing through the site (Figure $4 \mathrm{a}$ and $\mathrm{d}$, Table 2).

Contrary to our prediction, the size of the mean turning angle when chipmunks were moving towards the road decreased, rather than increased, with traffic amount (Table 3; Figure 5). Although the effect of traffic on turning angle size was statistically significant $(p=0.013)$ the amount of variation explained by traffic was low $\left(R^{2}=0.08\right)$. Traffic amount did not significantly affect the minimum (Table 4; Figure 6) or median (Table 5; Figure 7) distance from the road. Results of a power analysis suggested that we had a sample size large enough to detect an $R^{2}=0.17$ (i.e. effect size $\left[f^{2}\right]=0.2$ ) with a power of 0.8 for both analyses.

There was a slight negative effect of traffic on the proportion of chipmunks that climbed trees when tree density was controlled for (Table 6; Figure 8). The use of CWD decreased significantly as traffic increased when amount of CWD was controlled for (Table 7; Figure 9). Both of these results are opposite our predictions; however due to a low number of degrees of freedom these two results should be interpreted with caution.

\section{Discussion and conclusion}

Our results confirm that chipmunks avoid roads (Figure 3 ), as has been found in previous studies (McGregor 2004; Oxley et al. 1974). Our results do not support the 
hypothesis that chipmunks avoid roads because of traffic; none of our three predictions was supported. Below we review these results and discuss the likely mechanisms through which chipmunks avoid roads. In addition, we made two predictions based on the hypothesis that chipmunks respond to vehicles in the same way that they respond to large predators. Again, our results did not support these predictions. Following our discussion of road avoidance, we review the results on predator response and suggest a possible explanation. Finally, we summarize the implications of our findings.

Our first prediction was that if chipmunks avoid roads due to traffic then the probability of an animal crossing the road would decrease as traffic increases. Implicit in this prediction was the assumption that at least a few chipmunks would cross the road, particularly at low-traffic release sites. Only one of 62 pathways crossed the road. This result did not allow us to analyze the effect of traffic on the frequency of road crossing. It is also consistent with the notion that chipmunks avoid roads independently of traffic (McGregor 2004; Oxley et al. 1974), and in contrast to Richardson et al. (1997) who found that road avoidance increased with traffic amount for two vole species.

Second, we predicted that the size of turning angles should increase with traffic amount. We found very little effect of traffic on turning angle size in two analyses, and what effect we did find was opposite to our prediction: the clustering of exit bearings was near $180^{\circ}$ (i.e., away from the road) only at low traffic sites when a vehicle was passing by the site; and the mean size of the turning angle when chipmunks were heading towards the road decreased with increasing traffic volume. A possible explanation for the first result is that perhaps the individuals released at high traffic sites became acclimatized to traffic noise during the 5 minutes before the box lid was lifted. In the low 
traffic sites few vehicles would have passed during that time, so the animals responded when a vehicle was passing as the box lid was lifted. This suggests that chipmunks likely acclimatize very quickly to traffic noise.

Third, we predicted that if chipmunks avoid roads because of traffic emissions then they would venture closer to the road as traffic decreased. We found no effect of traffic amount on either the minimum distance from the road (Table 4) or the median distance from the road (Table 5). This finding is consistent with McGregor (2004) who found that densities of chipmunks and white-footed mice (Peromyscus leucopus) in roadside habitats were not affected by traffic amount. Note, however, that emissions aversion has been documented in other fauna such as songbirds (Forman et al. 2002; Reijnen et al. 1996).

These three results support the notion that chipmunks avoid the road itself and that road avoidance is independent of traffic amount. Furthermore, road aversion is not simply due to an unwillingness to move out of the forest into the open verge. Of the 62 pathways we traced, $25(40 \%)$ moved onto the roadside verge. Thus, important components of road avoidance occur while animals are moving within the roadside verge. Two possible explanations for this occurrence is a response by chipmunks to changes in verge vegetation structure or proximity to the road surface per se. Previous studies have found that the frequency of road crossing in forest-dwelling small mammals increased when vegetation complexity in road verges was artificially supplemented (Goosem 2001; McDonald \& St.Clair 2004b). Chipmunks are known to respond to microhabitat structure, especially when displaced beyond their home range (Bowers 1995). Thus, the structure and composition of verge vegetation may affect chipmunk movement. At the 
same time, chipmunks may be avoiding roads due to environmental gradients associated with the road surface per se such as changes to light, temperature, texture or odour. Support for this prediction is suggested by the fact that chipmunks may respond to different types of road surface composition (e.g. gravel, paved), since the structure of these environmental gradients change with road surface composition. For instance, Oxley et al. (1974) found that chipmunks crossed gravel roads more often than paved roads, although road surface composition and traffic amount were confounded in their study. Others have found that some small mammals respond to the composition of the road surface by altering their movement patterns even though these individuals did not avoid the road (Brock \& Kelt 2004; McDonald \& St. Clair 2004a). In our study, changes in verge vegetation structure and distance to the road surface are confounded so we cannot isolate these potential effects on chipmunk movement. Further research is needed to determine if changes in vegetation near roads or surface composition affect road aversion in chipmunks.

Our results did not support our predictions from the hypothesis that chipmunks would respond to traffic in a similar way that they respond to large predators. First, we predicted that more individuals would climb trees as traffic amount increases. This prediction was based on a study by Clarke et al. (1993), who found that chipmunks tend to climb trees when pursued by humans in unfamiliar habitat. Second, if chipmunks respond to vehicles as predators we expected their use of CWD for travel to increase with traffic amount. This prediction was based on Zollner and Crane's (2003) study in which chipmunks were observed using CWD more frequently than expected in less hospitable environments. We found that both the number of chipmunks that climbed trees and the 
use of CWD decreased with traffic amount (Table $6 \&$ Table 7). These results may again indicate that chipmunks become acclimatized to traffic noise quickly, particularly when traffic flow is constant (high traffic sites). At low traffic sites the noise of infrequent individual vehicles may cause a response similar to predator avoidance. Such avoidance of individual vehicles may reduce the mortality rate of chipmunks when crossing roads at low traffic sites. For example, Oxley et al. (1974) found that chipmunks comprised $42 \%$ of individual mammals observed crossing roads but only $11 \%$ of the mammalian roadkill detected within their study area.

Our results suggest that paved roads, irrespective of the traffic on them, reduce landscape connectivity (sensu Taylor et al. 1993) for chipmunks. It is often suggested that higher landscape connectivity is associated with higher population persistence because it reduces local extinction probabilities and increases recolonization of local extinctions (Fahrig \& Merriam 1985; Franken \& Hik 2004). Indeed, small mammal species are known to suffer from local extinctions in the study area (Henderson et al. 1985; Wegner \& Merriam 1979) and the recolonization of formerly occupied habitat may require dispersing individuals to cross roads. Thus, it seems reasonable to predict that roads reduce persistence of chipmunk populations. On the other hand, it has been suggested that population persistence may actually increase with increasing habitat fragmentation (see Fahrig 2003 for possible reasons). For example, some insect populations are more abundant near low-permeable edges and have higher population persistence in patches with such edges (Haynes \& Cronin 2006). Interestingly, McGregor (2004) found that chipmunks were more numerous in forest sites near roads than in forest interior sites, and Rtywinski (unpubl. data) found that white-footed mouse population densities increased 
with road density. Together these results suggest that roads might actually increase chipmunk population persistence. Determining which of these contrasting possibilities is correct will require a future study evaluating the effect of road density on chipmunk population abundance and distribution.

Although roads inhibit the movement of chipmunks, the amount of road crossing may still be enough to maintain genetic exchange across the region. Merriam et al. (1989) found that $8 \%$ of 115 white-footed mice living near roads crossed the road. They were unable to genetically identify sub-populations on the basis of the road boundary and attributed this to the movement across the road. We found that 1 in $62(\approx 2 \%)$ chipmunks crossed the roads in our study. This is likely an underestimate, as some individuals may have crossed after the tracking spool had expired. Oxley et al. (1974) found that approximately $3 \%$ of 179 chipmunks crossed roads during two years of trapping and McGregor (2004) found that $6 \%$ of 63 chipmunks living near roads crossed during her two-year study. Conrey and Mills (2001) found that 4\% of 234 individuals from two species of chipmunks (T. amoenus and T. ruficaudus) crossed two-lane highways and $0 \%$ crossed four-lane highways. With the exception of the four-lane highway, the observed road crossing frequency in chipmunk populations, between $2 \%$ and $6 \%$ of marked individuals, is slightly less than the observed rate of crossing in Merriam et al. (1989), but it exceeds the theoretical minimum of one migrant per generation needed to maintain a panmictic population (Wright 1969).

In conclusion, our results suggest that chipmunks avoid crossing roads, but we found no compelling evidence that chipmunks avoid roads because of traffic emissions. We detected a small but statistically significant response of chipmunks to vehicles at low- 
traffic sites only, possibly indicating that chipmunks become quickly acclimatized to traffic noise and other emissions at high traffic sites. Chipmunk populations are likely not strongly affected by mortality from traffic. Rather, we predict that the effect of roads on chipmunk population persistence is mainly due to population subdivision. Such subdivision could result in either an increase or a decrease in population persistence; future research is needed to determine the population-level effects of roads on chipmunks. 


\section{References}

Andrews, K. M., and J. W. Gibbons. 2005. How do highways influence snake movement? Behavioral responses to roads and vehicles. Copeia 772-782.

Bowers, M. A. 1995. Use of space and habitats by the eastern chipmunk, Tamias striatus. Journal of Mammalogy 76:12-21.

Bowman, J., and L. Fahrig. 2002. Gap crossing by chipmunks: an experimental test of landscape connectivity. Canadian Journal of Zoology-Revue Canadienne de Zoologie 80:1556-1561.

Brock, R. and D. Kelt. 2004. Influence of roads on the endangered Stephen's kangaroo rat (Dipodmys stephensi): are dirt and gravel roads different? Biological Conservation 118: 633-640

Burnett, S. 1992. Effects of a rainforest road on movements of small mammals: mechanisms and implications. Wildlife Research 19: 95-104

Caro, T. M., J. A. Shargel, and C. J. Stoner. 2000. Frequency of medium-sized mammal road kills in an agricultural landscape in California. American Midland Naturalist 144:362-369.

Carr, L. W., and L. Fahrig. 2001. Effect of road traffic on two amphibian species of differing vagility. Conservation Biology 15:1071-1078.

Clark, B. K., B. S. Clark, L. A. Johnson, and M. T. Haynie. 2001. Influence of roads on movements of small mammals. The Southwestern Naturalist 46:338-344.

Clarke, G.P., White, P., and S. Harris. 1998. Effects of roads on badger Meles meles populations in south-west England. Biological Conservation 86: 117-124

Clarke, M. F., K. B. Dasilva, H. Lair, R. Pocklington, D. L. Kramer, and R. L. Mclaughlin. 1993. Site Familiarity Affects Escape Behavior of the Eastern Chipmunk, Tamias-Striatus. Oikos 66:533-537

Clevenger, A. P., B. Chruszczc, and K. E. Gunson. 2003. Spatial patterns and factors influencing small vertebrate fauna road-kill aggregations. Biological Conservation 109:15-26.

Conrey R. and L.S. Mills. 2001. Do highways fragment small mammal populations? Proceedings of the International Conference on Ecology and Transportation, Keystone, CO, September 24-28, 2001. Raleigh, NC: Center for Transportation and the Environment, NC State University (March 2002): 448-457 
Dodd, C. K., W. J. Barichivich, and L. L. Smith. 2004. Effectiveness of a barrier wall and culverts in reducing wildlife mortality on a heavily traveled highway in Florida. Biological Conservation 118:619-631.

Fahrig, L. 2003. Effects of habitat fragmentation on biodiversity. Annual Review of Ecology, Evolution and Systematics. 34:487-515

Fahrig, L., J. H. Pedlar, S. E. Pope, P. D. Taylor, and J. F. Wegner. 1995. Effect of road traffic on amphibian density. Biological Conservation 73:177-182.

Fahrig, L. and G. Merriam. 1985. Habitat patch connectivity and population survival. Ecology 66: 1762-1768

Findlay, C. S., and J. Bourdages. 2000. Response time of wetland biodiversity to road construction on adjacent lands. Conservation Biology 14:86-94.

Forman, R.T.T., D. Sperling, J.A. Bissonette, A.P. Clevenger, C.D. Cutshall, V.H. Dale, L. Fahrig, R. France, C.R. Goldman, K. Heanue, J.A. Jones, F.J. Swanson, T. Turrentine, and T.C. Winter. 2003. Road ecology: Science and solutions. Island Press, Washington.

Forman, R. T. T., B. Reineking, and A. M. Hersperger. 2002. Road traffic and nearby grassland bird patterns in a suburbanizing landscape. Environmental Management 29:782-800.

Franken, R. and D. Hik. 2004. Influence of habitat quality, patch size and connectivity on colonization and extinction dynamics of collared pikas Ochotona collaris. Journal of Animal Ecology 73: 889-896

Getty, T. 1981. Territorial behavior of eastern chipmunks (Tamias striatus): encounter avoidance and spatial time sharing. Ecology 62: 915-921

Goosem, M. 2001. Effects of tropical rainforest roads on small mammals: inhibition of crossing movements. Wildlife Research 28: 351-364

Haynes, K. and J. Cronin. 2006. Interpatch movement and edge effects: the role of behaviural responses to the landscape matrix. Oikos 113: 43-54

Henderson, M., Merriam, G., and J. Wegner 1985. Patchy environments and species survival: chipmunks in an agricultural mosaic. Biological Conservation 31: 95105

Jaeger, J. A. G., J. Bowman, J. Brennan, L. Fahrig, D. Bert, J. Bouchard, N. Charbonneau, K. Frank, B. Gruber, and K. T. von Toschanowitz. 2005. Predicting when animal populations are at risk from roads: an interactive model of road avoidance behavior. Ecological Modelling 185:329-348. 
Koprowski, J. 2002. Handling tree squirrels with a safe and efficient restraint. Wildlife Society Bulletin. 30: 101-103

Kozel, R. and E. Fleharty. 1979. Movements of rodents across roads. The Southwestern Naturalist 24: 239-248

Loew, S. S. 1999. Sex-biased dispersal in eastern chipmunks, Tamias striatus. Evolutionary Ecology 13:557-577.

Mader, H.-J. 1984. Animal habitat isolation by roads and agricultural fields. Biological Conservation 29: 81-96

Mazerolle, M. J., M. Huot, and M. Gravel. 2005. Behavior of amphibians on the road in response to car traffic. Herpetologica 61:380-388.

Mcadam, A. G., and D. L. Kramer. 1998. Vigilance as a benefit of intermittent locomotion in small mammals. Animal Behaviour 55:109-117.

McClure, E. 1951. An analysis of animal victims on Nebraska's highways. Journal of Wildlife Management. 15: 410-420

McDonald, W., and C. C. St Clair. 2004a. Elements that promote highway crossing structure use by small mammals in Banff National Park. Journal of Applied Ecology 41:82-93.

McDonald, W. R., and C. C. St Clair. 2004b. The effects of artificial and natural barriers on the movement of small mammals in Banff National Park, Canada. Oikos 105:397-407.

McGregor, R. 2004. The effects of roads on small mammal movement. M.Sc. Thesis. Department of Biology at Carleton University, Ottawa, Ontario. 40pp.

Merriam, G., Koaziewicz, M., Tsuchiya, E. and K. Hawley. 1989. Barriers as boundaries for metapopulations and demes of Peromyscus leucopus in farm landscapes. Landscape Ecology 2: 227-235

Oxley, D.J., M.B. Fenton and G.R. Carmody. 1974. The effect of roads on populations of small mammals. Journal of Applied Ecology 11: 51-59.

Reijnen, R., R. Foppen, C. Terbraak, and J. Thissen. 1995. The effects of car traffic on Breeding Bird Populations in Woodland .3. reduction of density in relation to the proximity of main roads. Journal of Applied Ecology 32:187-202.

Richardson, J., Shore, R., Treweek, J., and S. Larkin. 1997. Are major roads a barrier to small mammals? Journal of Zoology. 243: 840-846

Rondinini C, and Doncaster CP. 2002. Roads as barriers to movement for hedgehogs. Functional Ecology 16 : 504-509 
Saeki, M., and D. W. Macdonald. 2004. The effects of traffic on the raccoon dog (Nyctereutes procyonoides viverrinus) and other mammals in Japan. Biological Conservation 118:559-571.

Snyder, D. 1982. Tamias striatus. Mammalian Species 168: 1-8

Swihart, R.K. and N.A. Slade. 1984. Road crossing in Sigmodon hispidus and Microtus ochrogaster. Journal of Mammalogy 65: 357-360

Taylor, P., Fahrig, L., Henein, K., and G. Merriam. 1993. Connectivity is a vital element of landscape structure. Oikos 68: 571-573

Wegner, J. and G. Merriam. 1979. Movement by birds and small mammals between a wood and adjoining farmland habitats. The Journal of Applied Ecology 16: 349 357

Wolfe, J. L. 1969. Observations on alertness and exploratory behavior in eastern chipmunks. American Midland Naturalist 81:249-\&.

Wright, S. 1969. Evolution and the genetics of populations. Vol. 2, The theory of gene frequencies. UCP: Chicago

Zollner, P. A. 2000. Comparing the landscape level perceptual abilities of forest sciurids in fragmented agricultural landscapes. Landscape Ecology 15:523-533.

Zollner, P. A., and K. J. Crane. 2003. Influence of canopy closure and shrub coverage on travel along coarse woody debris by eastern chipmunks (Tamias striatus).

American Midland Naturalist 150:151-157 
Table 1. Site data.

\begin{tabular}{crrrr}
\hline \hline Site & $\begin{array}{c}\text { Mean 60 minute traffic } \\
\text { count (standard } \\
\text { deviation) }\end{array}$ & $\begin{array}{c}\text { Categorical } \\
\text { traffic amount } \\
\text { (High/Low) }\end{array}$ & $\begin{array}{c}\text { Verge width on } \\
\text { release side of } \\
\text { the road (m) }\end{array}$ & $\begin{array}{c}\text { Distance between forest } \\
\text { edges across road } \\
(\mathrm{m})\end{array}$ \\
\hline $\mathrm{A}$ & $1185(590.38)$ & $\mathrm{H}$ & 22 & 42 \\
$\mathrm{~B}$ & $240(92.69)$ & $\mathrm{H}$ & 12 & 26 \\
$\mathrm{C}$ & $206(68.94)$ & $\mathrm{H}$ & 10 & 28 \\
$\mathrm{D}$ & $93(65.78)$ & $\mathrm{L}$ & 14 & 35 \\
$\mathrm{E}$ & $47(12.06)$ & $\mathrm{L}$ & 9 & 25 \\
$\mathrm{~F}$ & $46(12.97)$ & $\mathrm{L}$ & 9 & 23 \\
\hline \hline
\end{tabular}

Table 2. Summary statistics for the exit direction analysis. Vehicle refers to releases performed when a vehicle was passing through the site.

\begin{tabular}{|c|c|c|c|c|}
\hline & \multicolumn{2}{|c|}{ High traffic } & \multicolumn{2}{|c|}{ Low traffic } \\
\hline & Vehicle & No vehicle & Vehicle & No vehicle \\
\hline Number of observations & 22 & 14 & 16 & 16 \\
\hline Mean vector $(\mu)$ & $135^{\circ}$ & $226^{\circ}$ & $137^{\circ}$ & $193^{\circ}$ \\
\hline Length of mean vector $(r)$ & 0.278 & 0.172 & 0.402 & 0.267 \\
\hline Rao's spacing test $U(\mathrm{p})$ & $121(>0.50)$ & $143(>0.10)$ & $168(<0.05)$ & $134(>0.10)$ \\
\hline $\begin{array}{r}\mathrm{V} \text { test } \\
(\mathrm{V} ; \text { expected mean } \\
\left.180.00^{\circ}\right)\end{array}$ & 0.196 & 0.119 & 0.293 & 0.261 \\
\hline$V$ test $u(\mathrm{p})$ & $1.299(0.098)$ & $0.631(0.266)$ & $1.657(0.049)$ & $1.474(0.071)$ \\
\hline
\end{tabular}

Table 3. ANOVA table for the effect of traffic on the mean turning angle when chipmunks were moving towards the road.

\begin{tabular}{|c|c|c|c|c|c|c|c|}
\hline Source & $\begin{array}{l}\text { Type III sum } \\
\text { of squares }\end{array}$ & $\mathrm{df}$ & $\begin{array}{l}\text { Mean square } \\
\text { error }\end{array}$ & $\mathrm{F}$ & $\mathrm{p}$ & Estimate & $\begin{array}{c}\text { Standard } \\
\text { error }\end{array}$ \\
\hline Corrected model & 1143.193 & 1 & 1143.193 & 6.572 & 0.013 & & \\
\hline Intercept & 277760.623 & 1 & 277760.623 & 1596.683 & $<0.001$ & 85.515 & 7.440 \\
\hline $\log (60 \mathrm{~min}$. traffic $)$ & 1143.193 & 1 & 1143.193 & 6.572 & 0.013 & -8.619 & 3.362 \\
\hline Error & 10437.660 & 60 & 173.961 & & & & \\
\hline Total & 289341.475 & 62 & & & & & \\
\hline Corrected total & 11580.852 & 61 & & & & & \\
\hline
\end{tabular}


Table 4. ANOVA table for minimum distance from the road. Data $(n=10)$ from one site (Site A) were excluded from this analysis because this site had a verge width twice the typical verge width of the other sites [Table 1].

\begin{tabular}{rrrrrrrr}
\hline \hline \multicolumn{1}{c}{ Source } & $\begin{array}{c}\text { Type III sum } \\
\text { of squares }\end{array}$ & \multicolumn{1}{c}{$\begin{array}{c}\text { Mean square } \\
\text { error }\end{array}$} & \multicolumn{1}{l}{ F } & p & $\begin{array}{c}\text { Estimate } \\
\begin{array}{c}\text { Standard } \\
\text { error }\end{array}\end{array}$ \\
\hline Corrected Model & 23.827 & 2 & 11.913 & 0.561 & 0.574 & & \\
Intercept & 22.859 & 1 & 22.859 & 1.076 & 0.305 & 5.545 & 5.346 \\
Log (60min. traffic) & 22.438 & 1 & 22.438 & 1.056 & 0.309 & 1.988 & 1.934 \\
Length of pathway & 0.046 & 1 & 0.046 & 0.002 & 0.963 & -0.001 & 0.024 \\
Error & 1041.014 & 49 & 21.245 & & & & \\
Total & 5619.417 & 52 & & & & & \\
Corrected total & 1064.841 & 51 & & & & & \\
\hline \hline
\end{tabular}

Table 5. ANOVA table for median distance from the road. Data $(n=10)$ from one site (Site A) were excluded from this analysis because this site had a verge width twice the typical verge width of the other sites [Table 1].

\begin{tabular}{rrrrrrrr}
\hline \hline \multicolumn{1}{c}{ Source } & $\begin{array}{c}\text { Type III sum } \\
\text { of squares }\end{array}$ & \multicolumn{1}{c}{$\begin{array}{c}\text { Mean square } \\
\text { error }\end{array}$} & \multicolumn{1}{l}{ f } & p & \multicolumn{2}{c}{$\begin{array}{c}\text { Estimate } \\
\text { error }\end{array}$} \\
\hline Corrected model & 237.427 & 2 & 118.714 & 1.202 & 0.309 & & \\
Intercept & 14.214 & 1 & 14.214 & 0.144 & 0.706 & 4.373 & 11.524 \\
Log (60min. traffic) & 136.380 & 1 & 136.380 & 1.381 & 0.246 & 4.901 & 4.170 \\
Length of pathway & 148.174 & 1 & 148.174 & 1.501 & 0.226 & 0.064 & 0.052 \\
Error & 4838.119 & 49 & 98.737 & & & & \\
Total & 30167.264 & 52 & & & & & \\
Corrected Total & 5075.546 & 51 & & & & & \\
\hline \hline
\end{tabular}

Table 6. ANOVA table for proportion of chipmunks that climbed trees at each site. Mean traffic is the mean of the log normal 60 minute traffic count from each release at a given site

\begin{tabular}{rrrrrrrrr}
\hline \hline & $\begin{array}{c}\text { Type III sum } \\
\text { of squares }\end{array}$ & \multicolumn{3}{c}{$\begin{array}{c}\text { Mean square } \\
\text { error }\end{array}$} & f & p & \multicolumn{2}{c}{$\begin{array}{c}\text { Standard } \\
\text { Estimate }\end{array}$} \\
\hline Corrected model & 0.077 & 2 & 0.038 & 3.160 & 0.183 & & \\
Intercept & 0.086 & 1 & 0.086 & 7.098 & 0.076 & 1.124 & 0.422 \\
& & & & & & & \\
Tree density & 0.001 & 1 & 0.001 & 0.052 & 0.834 & -1.032 & 4.519 \\
Mean traffic & 0.076 & 1 & 0.076 & 6.254 & 0.088 & -0.240 & 0.096 \\
Error & 0.036 & 3 & 0.012 & & & & \\
Total & 1.820 & 6 & & & & & \\
Corrected Total & 0.113 & 5 & & & & & \\
\hline \hline
\end{tabular}


Table 7. ANOVA table for the mean use of coarse woody debris by chipmunks. Mean traffic is the mean of the log normal 60 minute traffic count from each release at a given site.

\begin{tabular}{|c|c|c|c|c|c|c|c|}
\hline & $\begin{array}{c}\text { Type III sum } \\
\text { of squares }\end{array}$ & df & $\begin{array}{c}\text { Mean square } \\
\text { error }\end{array}$ & $\mathrm{F}$ & $\mathrm{p}$ & Estimate & $\begin{array}{c}\text { Standard } \\
\text { error }\end{array}$ \\
\hline Corrected model & 0.051 & 2 & 0.025 & 20.018 & 0.018 & & \\
\hline Intercept & 0.009 & 1 & 0.009 & 6.863 & 0.079 & 0.200 & 0.077 \\
\hline $\begin{array}{l}\text { Coarse woody } \\
\text { debris amount }\end{array}$ & 0.029 & 1 & 0.029 & 22.610 & 0.018 & 0.001 & $<0.001$ \\
\hline Mean traffic & 0.022 & 1 & 0.022 & 17.699 & 0.025 & -0.128 & 0.030 \\
\hline Error & 0.004 & 3 & 0.001 & & & & \\
\hline Total & 0.118 & 6 & & & & & \\
\hline Corrected total & 0.055 & 5 & & & & & \\
\hline
\end{tabular}




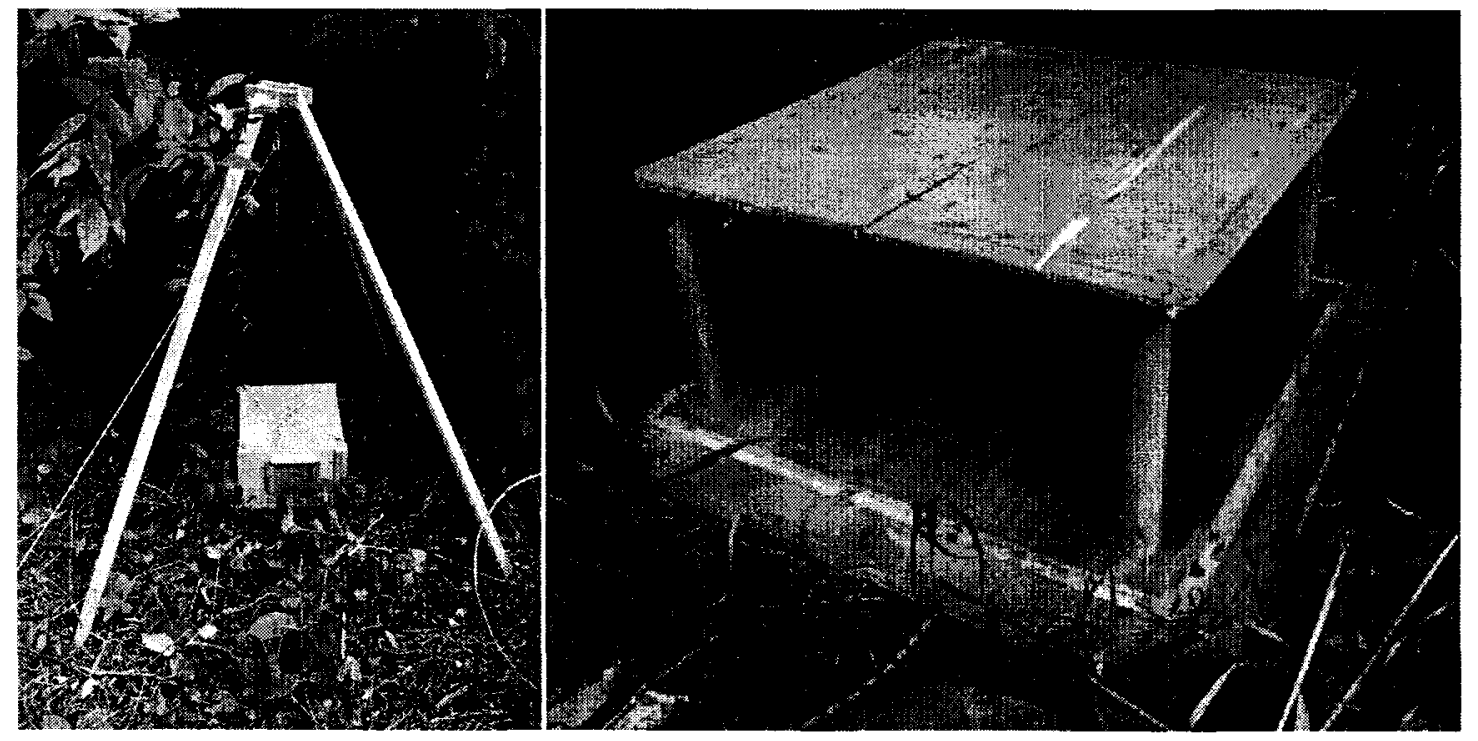

Figure 1. Mechanism for releasing individual chipmunks. The left photo shows the tripod and release device as it appeared prior to release of an animal. The right photo shows the false roof after the outer box has been removed. 


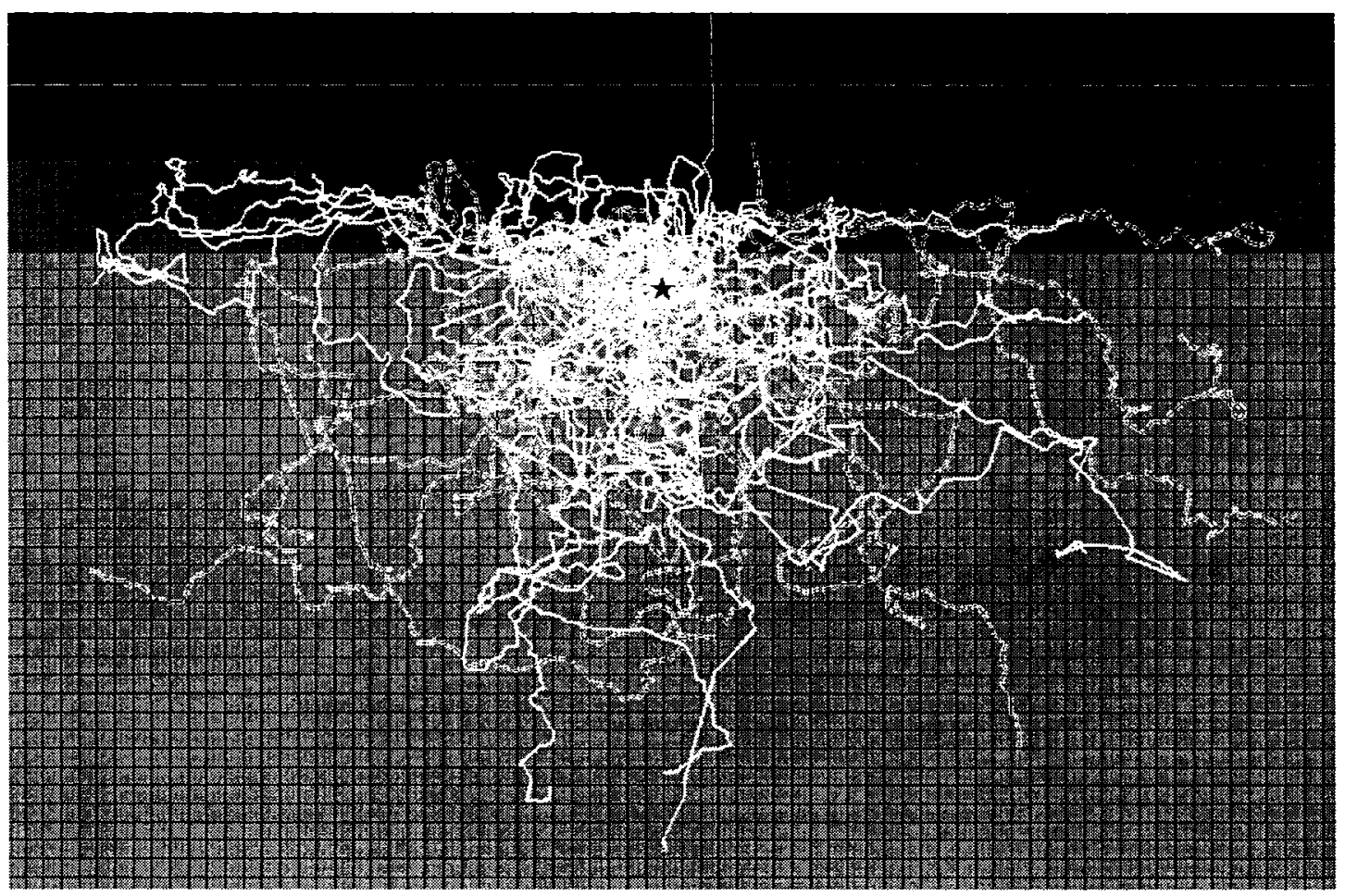

Figure 2. Graphical representation of all pathways greater than $40 \mathrm{~m}$ in length. Solid lines are pathways at low traffic sites and the double-dashed line are pathways from high traffic sites. The dark gray area represents the verge, the light gray area is the forest and the black area is the road surface. The approximate location of the release point is indicated by the black star. Each grid cell represents $2 \mathrm{~m}^{2}$. The mean verge width of Sites B-F was used for this figure. Site A was excluded because its verge width was almost twice as large as the verge width of the other sites. 
a) Vehicle/ high traffic

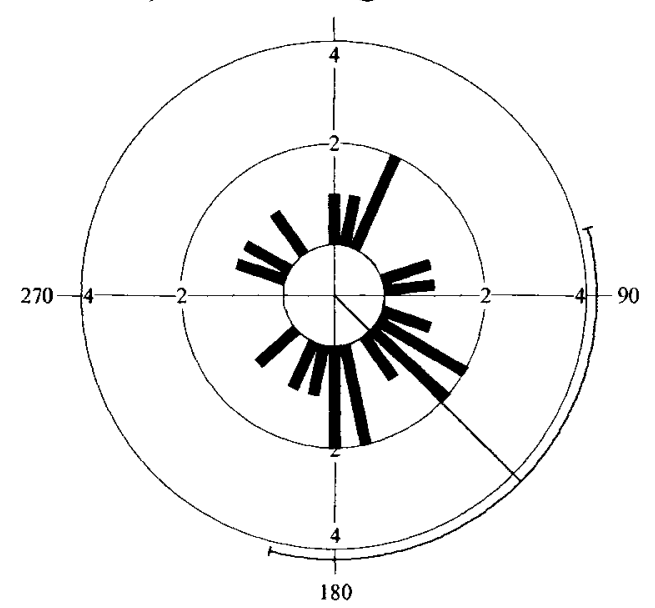

c) Vehicle/ low traffic

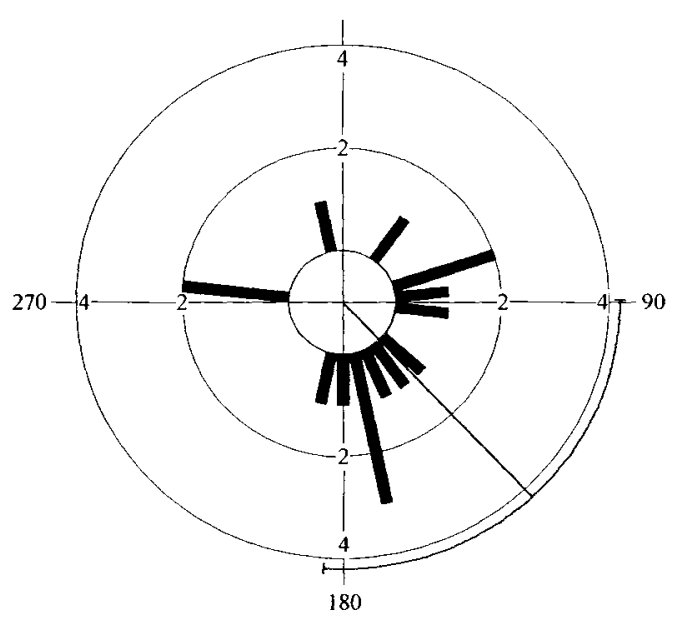

b) No vehicle/ high traffic



d) No vehicle/ low traffic

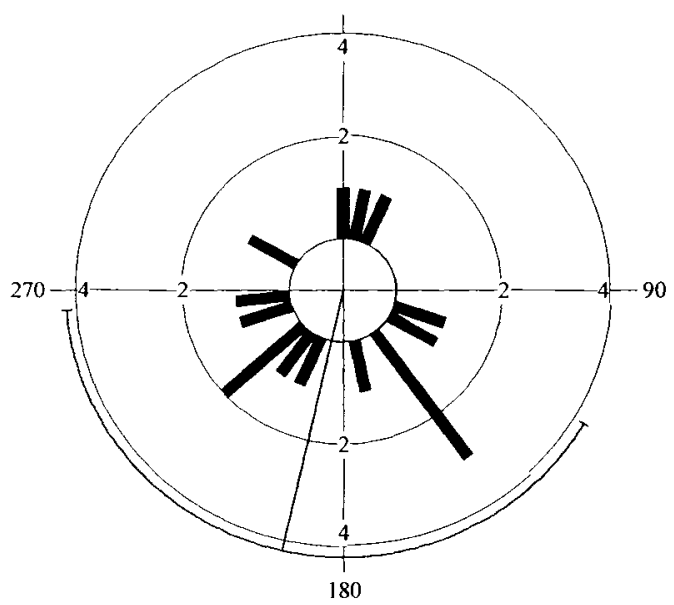

Figure 3. Histograms of exit direction bearings. Bars represent a width of $12^{\circ}$, concentric rings indicate a frequency of 2 pathways. Numbers outside of the circle are the bearings of the cardinal directions with $0^{\mathbf{o}}$ indicating movement directly towards the road. The black vector is the mean direction and the arc outside of the circle is the $95 \%$ confidence interval. Vehicle refers to releases performed when there was a vehicle passing through the site. 


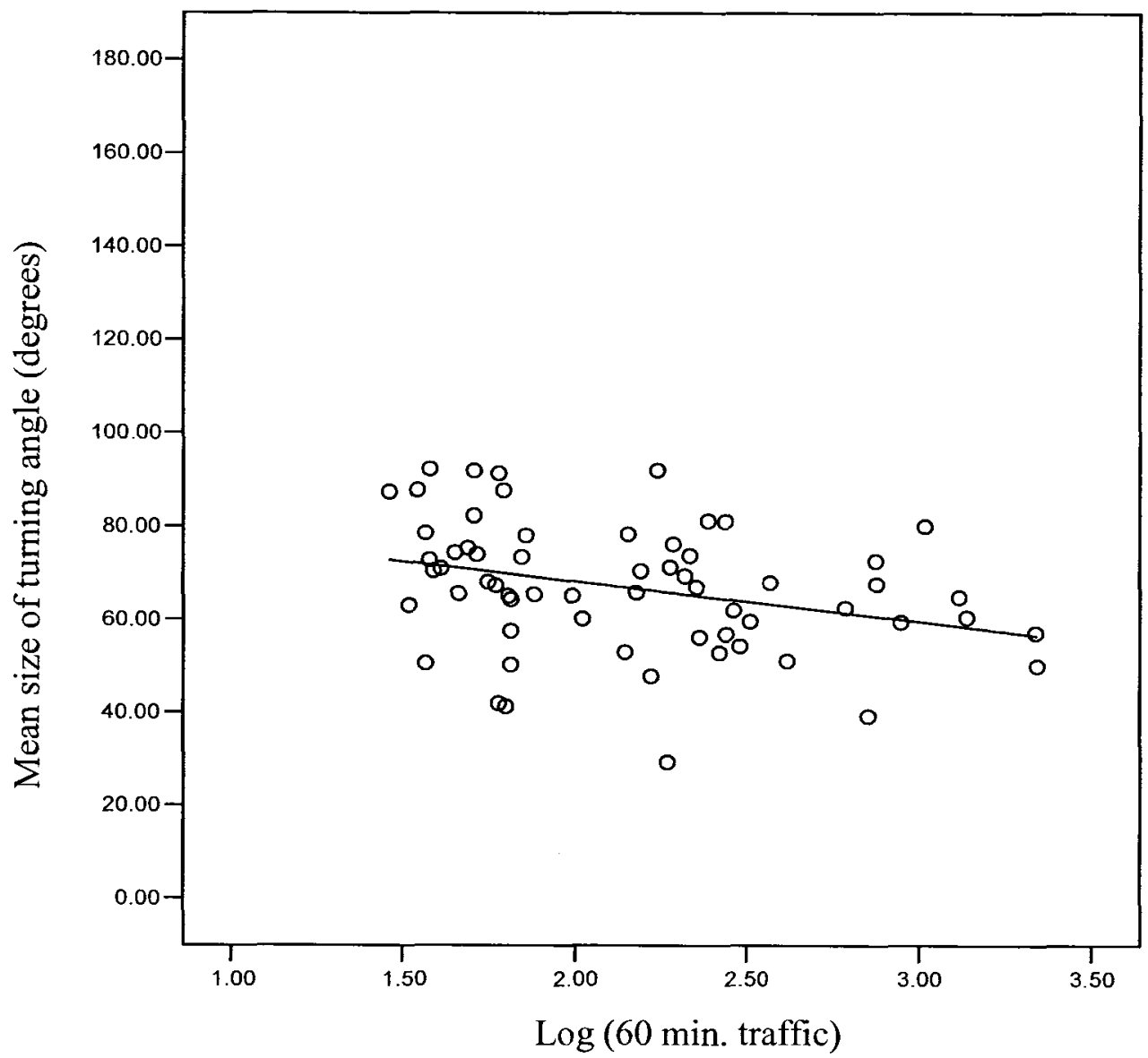

Figure 4. Effect of traffic amount on the mean turning angle when chipmunks were heading towards the road $\left(315^{\circ}\right.$ to $\left.45^{\circ}\right)$. Adjusted $\mathrm{R}^{2}=0.084$ for the model. 


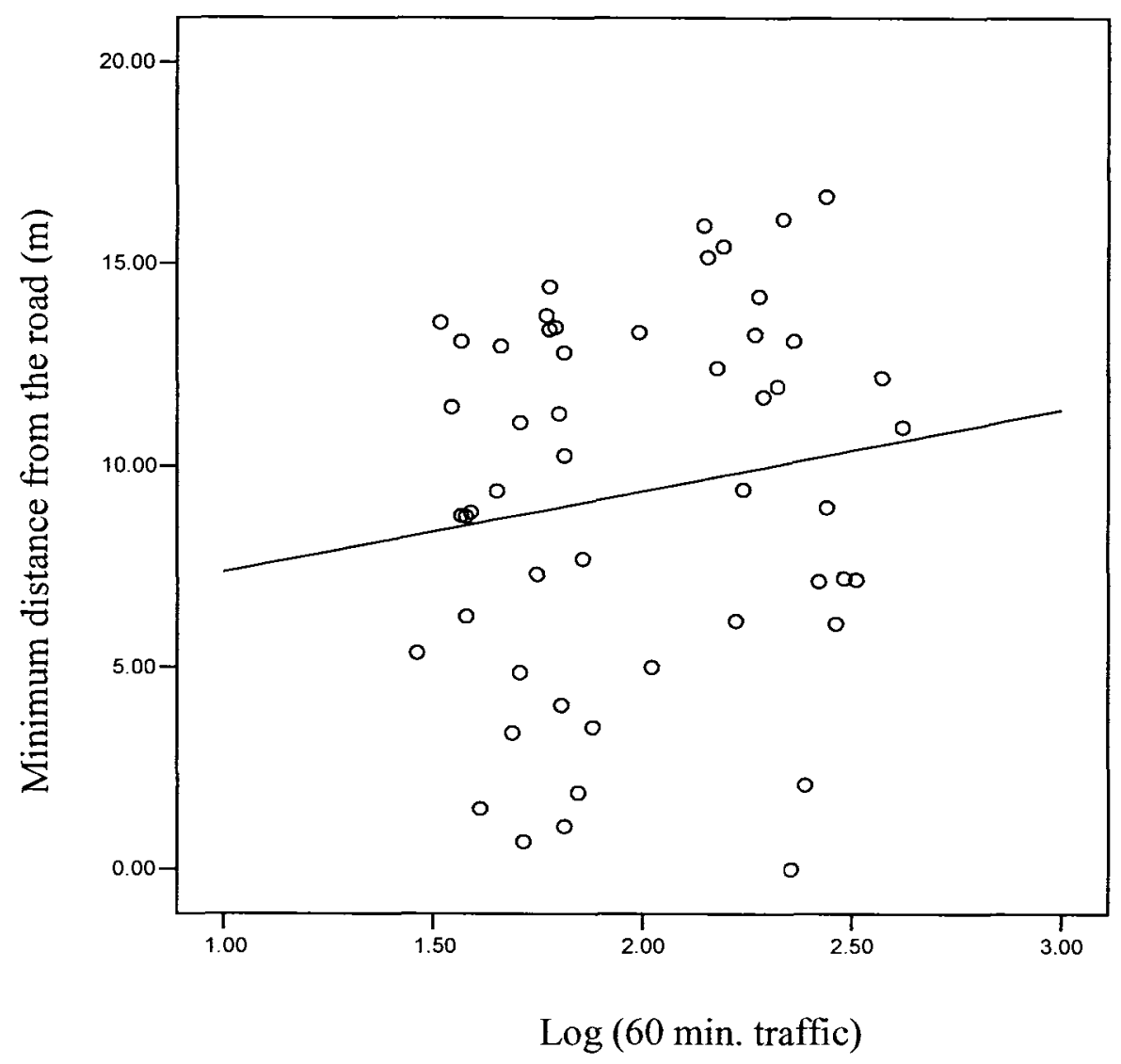

Figure 5. Effect of traffic amount on minimum distance from the road. Site A was excluded from this analysis; see text for explanation. Adjusted $\mathrm{R}^{2}<0.01$ for the model. 


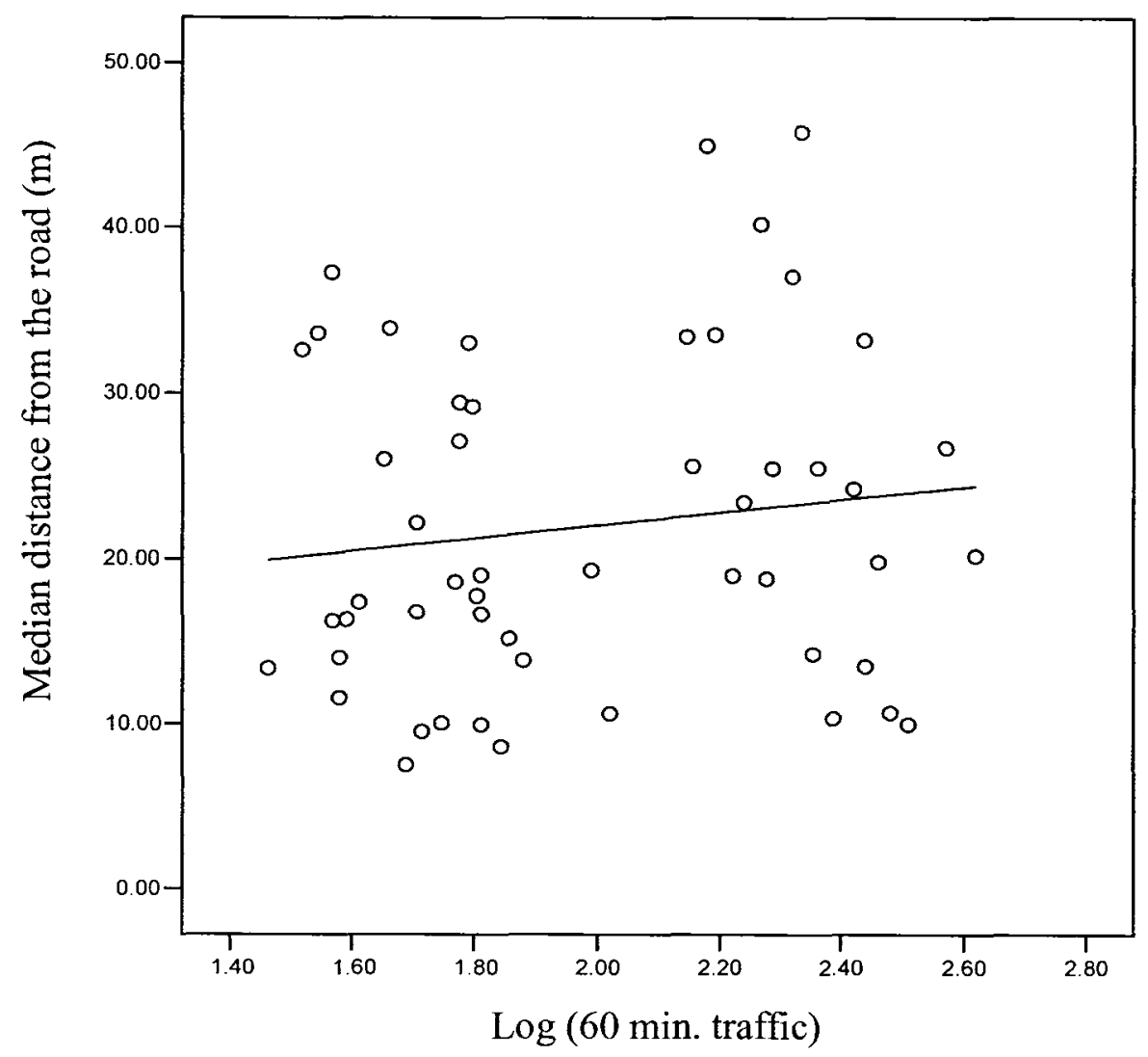

Figure 6. Effect of traffic amount on median distance from the road. Site A was excluded from this analysis; see text for explanation. Adjusted $\mathrm{R}^{2}<0.01$ for the model. 


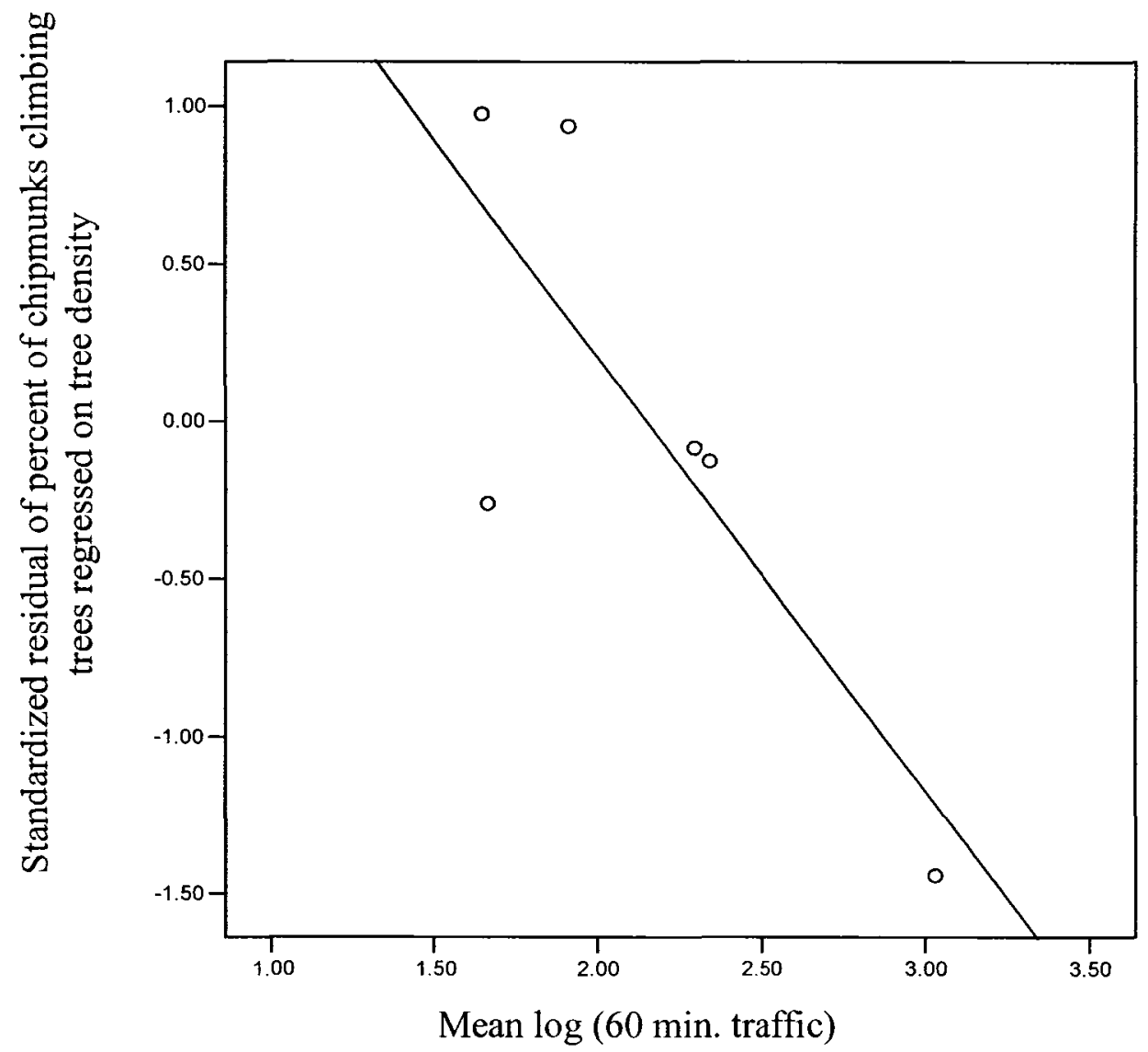

Figure 7. Relationship between use of trees by chipmunks and traffic amount at six test sites. Residuals from the percent of chipmunks climbing trees regressed on tree density were plotted against traffic amount, to illustrate the effect of traffic amount when tree dispersion is controlled for.

Adjusted $\mathrm{R}^{2}=0.464$ for the model. 


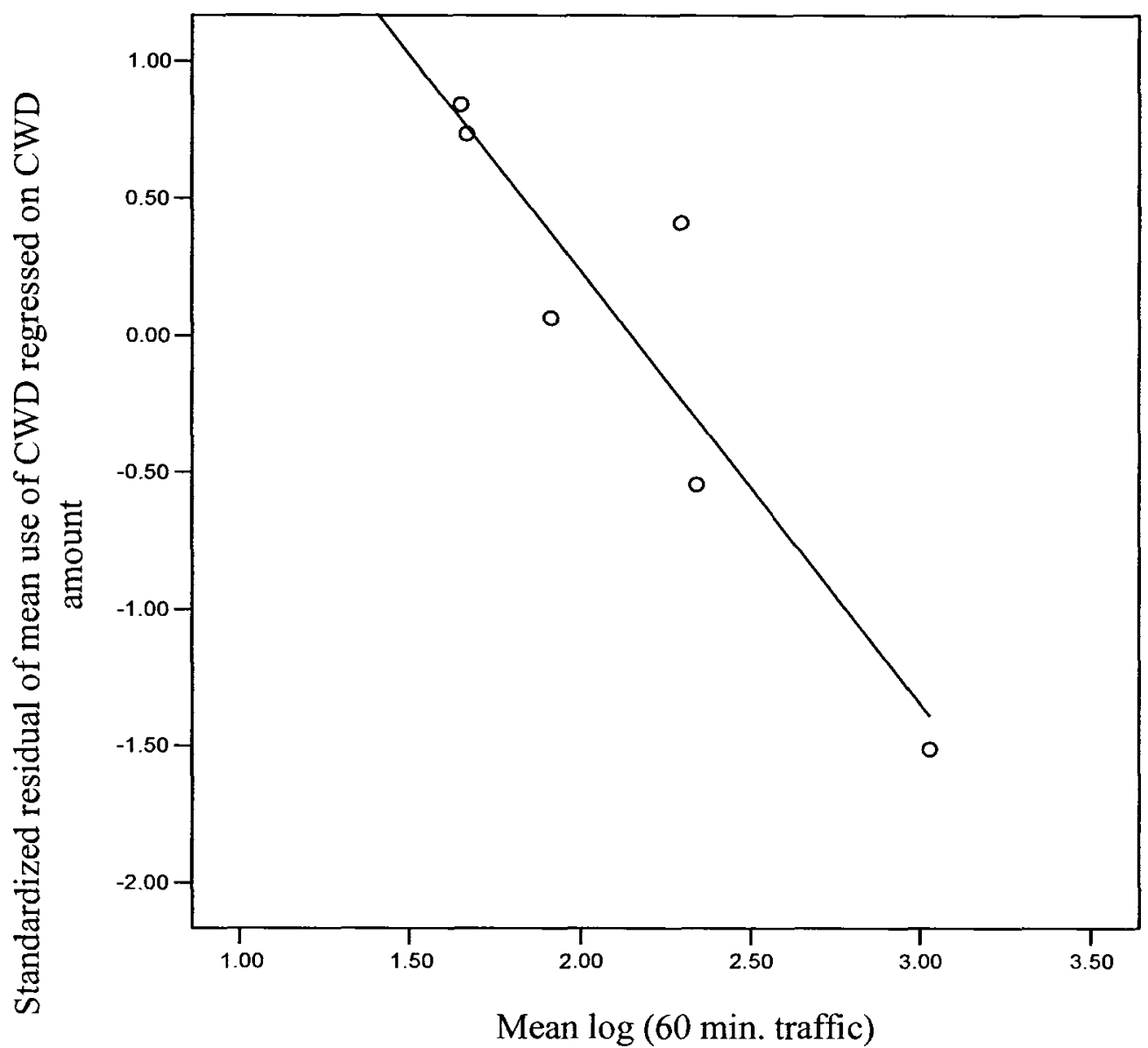

Figure 8. Relationship between use of coarse woody debris and traffic amount at six test sites. Residuals from CWD amount at each site regressed on the mean proportion of each pathway that ran along CWD, to illustrate the effect of traffic amount when CWD amount is controlled for.. Adjusted $\mathrm{R}^{2}=0.884$ for the model. 
Appendix A. Number of chipmunks contributed by each trapping site to each release site and distances between all pairs of sites.

\begin{tabular}{|c|c|c|c|c|c|c|c|c|c|c|c|c|c|}
\hline \multirow[b]{3}{*}{$\begin{array}{c}\text { Trapping } \\
\text { Site }\end{array}$} & \multicolumn{13}{|c|}{ Release Site } \\
\hline & $\mathrm{A}$ & & B & & $\mathrm{C}$ & & D & & $\mathrm{E}$ & & $\mathrm{F}$ & & Total \\
\hline & $\begin{array}{r}\text { Distance } \\
(\mathrm{m}) \\
\end{array}$ & $\mathrm{n}$ & 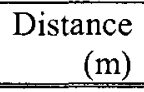 & $\mathrm{n}$ & 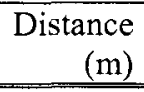 & $\mathrm{n}$ & $\begin{array}{r}\begin{array}{r}\text { Distance } \\
(\mathrm{m})\end{array} \\
\end{array}$ & $\mathrm{n}$ & $\begin{array}{r}\begin{array}{r}\text { Distance } \\
(\mathrm{m})\end{array} \\
\end{array}$ & $\mathrm{n}$ & $\begin{array}{r}\text { Distance } \\
(\mathrm{m}) \\
\end{array}$ & $\mathrm{n}$ & $\mathrm{n}$ \\
\hline 1 & 1210 & 0 & 23346 & 9 & 28216 & 3 & 32931 & 4 & 44510 & 5 & 19471 & 5 & 26 \\
\hline 2 & 6869 & 3 & 17643 & 0 & 22739 & 2 & 27201 & 0 & 38582 & 0 & 15217 & 1 & 6 \\
\hline 3 & 20861 & 3 & 9426 & 0 & 11050 & 1 & 16856 & 2 & 32084 & 0 & 240 & 0 & 6 \\
\hline 4 & 23985 & 5 & 831 & 0 & 5682 & 2 & 10070 & 3 & 23920 & 4 & 8780 & 2 & 16 \\
\hline 5 & 25749 & 2 & 2188 & 0 & 5901 & 4 & 8423 & 3 & 21101 & 1 & 11797 & 3 & 13 \\
\hline 6 & 52139 & 0 & 30906 & 1 & 29584 & 0 & 23985 & 0 & 8002 & 0 & 40197 & 0 & 1 \\
\hline Total & & 13 & & 10 & & 12 & & 12 & & 10 & & 11 & 68 \\
\hline
\end{tabular}


Appendix B. Coordinates of trapping sites, given in MTM Zone 9 Projection.

\begin{tabular}{crr}
\hline Site & Easting $(\mathrm{m})$ & Northing(m) \\
\hline \hline 1 & 339804 & 5002097 \\
2 & 345739 & 5001976 \\
3 & 355195 & 4989868 \\
4 & 361725 & 4995457 \\
5 & 364073 & 4997351 \\
6 & 388753 & 5002647 \\
7 & 390832 & 5007993 \\
\hline
\end{tabular}

Appendix C. Coordinates of release sites, given in MTM Zone 9 Projection.

\begin{tabular}{crr}
\hline Site & Easting $(\mathrm{m})$ & Northing(m) \\
\hline \hline A & 338938 & 5002941 \\
B & 362343 & 4996012 \\
C & 366074 & 4991800 \\
D & 371627 & 4993625 \\
E & 384296 & 5003376 \\
G & 354954 & 4989867 \\
\hline
\end{tabular}


Appendix D. Summary data of chipmunks used in this study. All references to dates occurred during 2004. Shaded rows indicate data excluded from regression analyses. Data are available in Appendix F. Car refers to the passing of a vehicle in the site when the animal was released with $Y$ indicating the presence of a vehicle. The mean turning angle is only calculated for sequential pathway segments when the first segment was heading towards the road and the second segment deviated more than $20^{\circ}$ from the previous bearing.

\begin{tabular}{|c|c|c|c|c|c|c|c|c|c|c|c|c|c|c|c|c|}
\hline $\begin{array}{l}\text { Animal } \\
\text { ID }\end{array}$ & $\begin{array}{l}\text { Release } \\
\text { Site }\end{array}$ & Date & $\begin{array}{c}\text { Time } \\
\text { Released }\end{array}$ & $\begin{array}{l}\text { Trap } \\
\text { Site }\end{array}$ & $\begin{array}{l}\text { Mass } \\
(\mathrm{g})\end{array}$ & $\begin{array}{l}\text { Age } \\
(\mathrm{a} / \mathrm{j})\end{array}$ & $\begin{array}{c}\text { Sex } \\
(\mathrm{m} / \mathrm{f})\end{array}$ & $\begin{array}{c}\text { Car } \\
(\mathrm{y} / \mathrm{n})\end{array}$ & $\begin{array}{l}60 \\
\text { Minute } \\
\text { Traffic } \\
\text { Count }\end{array}$ & $\begin{array}{l}\text { Total } \\
\text { Path } \\
\text { Length } \\
(\mathrm{m})\end{array}$ & $\begin{array}{c}\% \text { of } \\
\text { path } \\
\text { along } \\
\text { CWD }\end{array}$ & $\begin{array}{c}\text { Exit } \\
\text { Bearing } \\
\left(0^{\circ}\right)\end{array}$ & $\begin{array}{c}\text { Tree } \\
\text { Climbs }\end{array}$ & $\begin{array}{c}\text { Mean } \\
\text { Turning } \\
\text { Angle }\left(^{\circ}\right)\end{array}$ & $\begin{array}{c}\text { Min. } \\
\text { Distanc } \\
\text { e From } \\
\text { Road } \\
\text { (in) }\end{array}$ & $\begin{array}{l}\text { Med. } \\
\text { Distanc } \\
\text { e From } \\
\text { Road } \\
(\mathrm{m})\end{array}$ \\
\hline 1 & A & Jul. 06 & 1311 & 4 & 88 & 1 & $\mathrm{M}$ & y & 8222 & -3047 & $\sqrt{2}+x_{2}$ & 27 & 0 & * & r & +2 \\
\hline 2 & A & Jul-08 & 1640 & 4 & 114 & A & $\mathrm{M}$ & $\mathrm{Y}$ & 2211 & 176.19 & $0.89 \%$ & 325 & 2 & 50.13 & 11.78 & 21.20 \\
\hline 3 & A & Jul-13 & 1001 & 4 & 98 & A & $M$ & $\mathrm{Y}$ & 714 & 178.67 & $1.86 \%$ & 143 & 1 & 39.29 & 9.45 & 34.79 \\
\hline 4 & A & Jul-18 & 1459 & 3 & 102 & A & M & $\mathrm{Y}$ & 1380 & 168.27 & $0.00 \%$ & 205 & 0 & 60.53 & 19.90 & 25.93 \\
\hline 5 & A & Jul-19 & 1153 & 2 & 118 & A & M & $\mathrm{Y}$ & 612 & 164.86 & $1.83 \%$ & 189 & 5 & 62.62 & 15.29 & 19.68 \\
\hline 6 & A & Jul-21 & 1454 & 2 & 92 & A & $\mathrm{F}$ & $\mathrm{Y}$ & 1044 & 115.47 & $1.81 \%$ & 183 & 0 & 80.1 & 25.89 & 43.11 \\
\hline 7 & A & Jul-25 & 1154 & 2 & 102 & A & $M$ & $Y$ & 752 & 177.65 & $6.05 \%$ & 135 & 0 & 72.67 & 13.74 & 32.61 \\
\hline 8 & A & $\operatorname{dal}-26$ & 41354 & 3 & 92 & A & $\mathrm{u}$ & Y & .1650 & 120.28 & $2 *$ & 275 & 0 & + & * & 2 \\
\hline 9 & A & Jul-27 & 1351 & 3 & 112 & $A$ & $\mathrm{M}$ & Y & 887 & 174.42 & $3.80 \%$ & 125 & 1 & 59.54 & 25.24 & 43.64 \\
\hline 10 & A & ind 08 & 1055 & 4 & 115 & A & $\mathrm{M}$ & Y & 1080 & 18.39 & 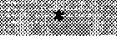 & 27 & 0 & * & et. & $*$ \\
\hline 11 & A & Jun-10 & 1600 & 4 & 120 & A & $\mathbf{M}$ & $\mathrm{N}$ & 1311 & 170.87 & $10.65 \%$ & 189 & 0 & 64.89 & 6.51 & 24.47 \\
\hline 12 & A & Jun-27 & 1705 & 5 & 80 & $\mathrm{~J}$ & $\mathrm{~F}$ & $\mathrm{~N}$ & 2185 & 107.59 & $3.10 \%$ & 339 & 3 & 57.23 & 19.77 & 24.80 \\
\hline 13 & A & Jun-29 & 1358 & 5 & 80 & $\mathrm{~J}$ & $\mathrm{M}$ & $N$ & 756 & 116.97 & $0.46 \%$ & 123 & 0 & 67.73 & 25.48 & 31.98 \\
\hline 14 & B & Jul.05 & 1438 & 1 & 70 & J & $\mathrm{M}$ & $\mathrm{N}$ & 56 & 95.25 & $5.15 \%$ & 296 & 1 & 68.17 & 7.33 & 10.04 \\
\hline 15 & B & Jul-13 & 1311 & 1 & 98 & A & $M$ & Y & 46 & 169.73 & $9.70 \%$ & 138 & 2 & 65.67 & 12.96 & 33.90 \\
\hline 16 & B & Jul-19 & 1354 & 1 & 110 & A & $\mathrm{F}$ & $N$ & 39 & 102.82 & $6.08 \%$ & 228 & 1 & 70.57 & 8.86 & 16.34 \\
\hline 17 & B & Jul-1! & 1350 & 1 & 110 & A & $\mathrm{F}$ & $\mathrm{Y}$ & 51 & 165.84 & $22.45 \%$ & 176 & 0 & 91.89 & 11.07 & 22.15 \\
\hline 18 & B & Jun-10 & 1317 & 1 & 105 & $J$ & $\mathrm{~F}$ & $\mathrm{~N}$ & 38 & 111.35 & $10.54 \%$ & 164 & 0 & 92.25 & 8.76 & 11.58 \\
\hline 19 & B & Jun-20 & 1625 & 1 & 70 & J & $\mathrm{F}$ & $\mathrm{Y}$ & 76 & 105.13 & $8.78 \%$ & 34 & 2 & 65.52 & 3.52 & 13.84 \\
\hline 20 & B & Jun-28 & 0900 & 1 & 105 & A & $\mathrm{F}$ & Y & 37 & 101.63 & $13.03 \%$ & 280 & 3 & 50.67 & 8.78 & 16.26 \\
\hline 21 & B & $\begin{array}{c}\text { Jun-30 } \\
\text { May- }\end{array}$ & 1107 & 1 & 72 & $\mathrm{~J}$ & $\mathrm{M}$ & Y & 37 & 110.02 & $14.98 \%$ & 170 & 0 & 78.67 & 13.08 & 37.26 \\
\hline$* * * 22$ & B & $\begin{array}{r}10 \\
\text { May- }\end{array}$ & 1445 & 6 & 100 & A & $\mathbf{M}$ & $\mathbf{N}$ & 52 & 100.39 & $0.00 \%$ & 220 & 2 & 74.07 & $<0.00$ & $\begin{array}{r}9.52 \\
26.01\end{array}$ \\
\hline 23 & B & 18 & 1628 & ] & 110 & A & M & $\mathrm{N}$ & 45 & 166.54 & $40.19 \%$ & 246 & 2 & 74.43 & 9.39 & \\
\hline 24 & $\mathrm{C}$ & Jul-04 & 1654 & 5 & 128 & A & $M$ & $\mathrm{~N}$ & 33 & 145.91 & $29.46 \%$ & 144 & 1 & 63.14 & 13.55 & 32.59 \\
\hline
\end{tabular}






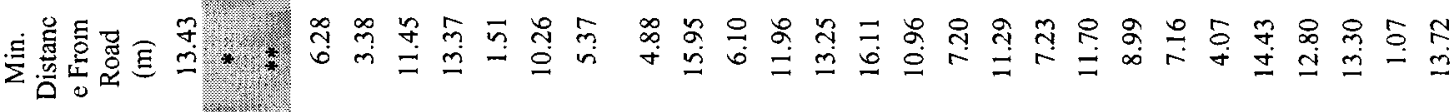



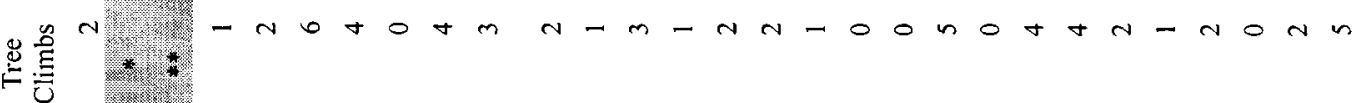
离䲿

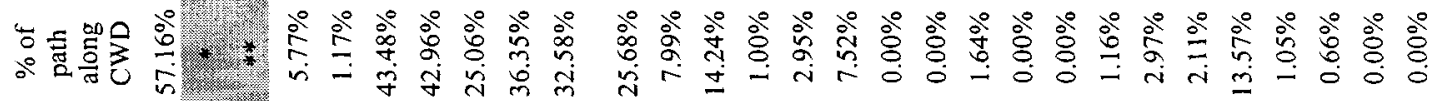

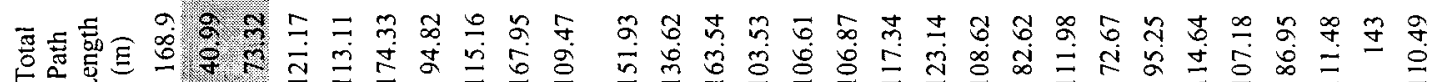

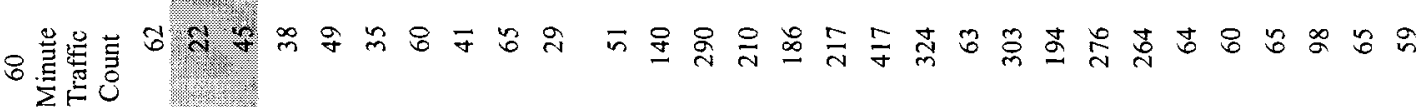

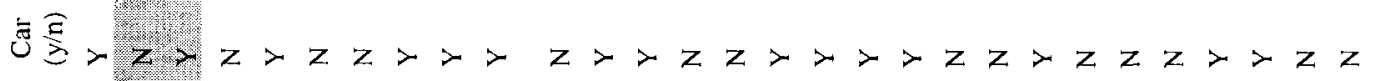

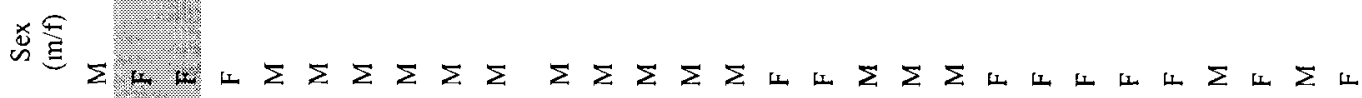

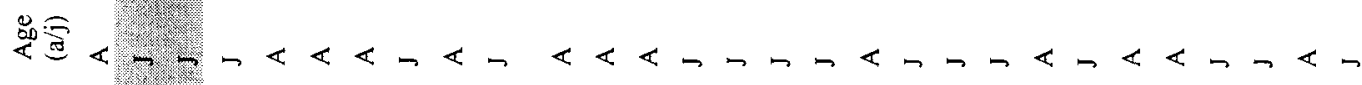





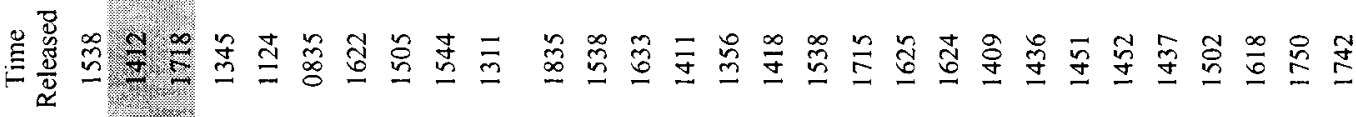

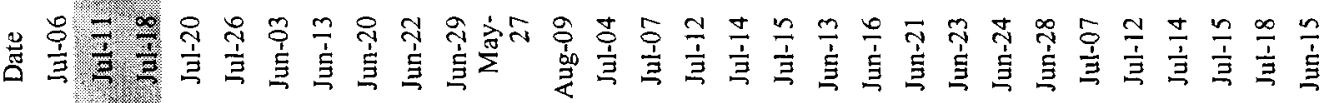
造

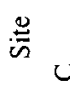

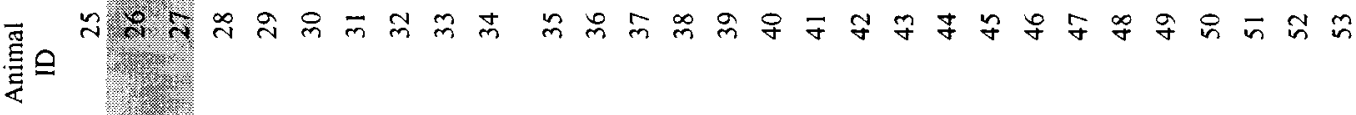




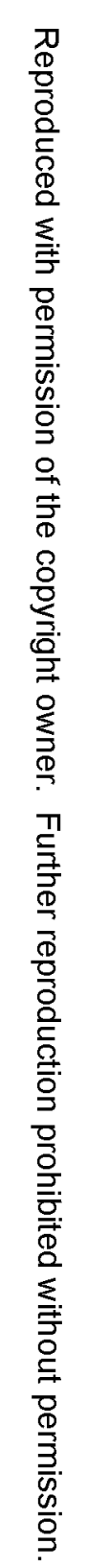

\begin{tabular}{|c|c|c|c|c|c|c|c|c|c|c|c|c|c|c|c|c|}
\hline $\begin{array}{l}\text { Animal } \\
\text { ID }\end{array}$ & $\begin{array}{l}\text { Release } \\
\text { Site }\end{array}$ & Date & $\begin{array}{l}\text { Time } \\
\text { Released }\end{array}$ & $\begin{array}{l}\text { Trap } \\
\text { Site }\end{array}$ & $\begin{array}{c}\text { Mass } \\
(\mathrm{g})\end{array}$ & $\begin{array}{l}\text { Age } \\
(\mathrm{a} / \mathrm{j})\end{array}$ & $\begin{array}{c}\text { Sex } \\
(\mathrm{m} / \mathrm{f})\end{array}$ & $\begin{array}{c}\mathrm{Car} \\
(\mathrm{y} / \mathrm{n})\end{array}$ & $\begin{array}{c}60 \\
\text { Minute } \\
\text { Traffic } \\
\text { Count }\end{array}$ & $\begin{array}{l}\text { Total } \\
\text { Path } \\
\text { Length } \\
\text { (m) }\end{array}$ & $\begin{array}{l}\% \text { of } \\
\text { path } \\
\text { along } \\
\text { CWD }\end{array}$ & $\begin{array}{c}\text { Exit } \\
\text { Bearing } \\
\left({ }^{\circ}\right)\end{array}$ & $\begin{array}{c}\text { Tree } \\
\text { Climbs }\end{array}$ & $\begin{array}{c}\text { Mean } \\
\text { Turning } \\
\text { Angle }\left(^{(0)}\right.\end{array}$ & $\begin{array}{l}\text { Min, } \\
\text { Distanc } \\
\text { e From } \\
\text { Road } \\
\text { (In) }\end{array}$ & $\begin{array}{c}\text { Med. } \\
\text { Distanc } \\
\text { e From } \\
\text { Road } \\
\text { (m) }\end{array}$ \\
\hline 54 & E & Jun-16 & 1715 & 4 & 65 & J & $\mathrm{F}$ & $\mathrm{Y}$ & 275 & 95.01 & $6.90 \%$ & 188 & 2 & 81.09 & 16.67 & 33.21 \\
\hline 55 & E & Jun-24 & 1710 & 4 & 70 & J & M & $\mathrm{Y}$ & 105 & 116.23 & $1.52 \%$ & 78 & 4 & 60.25 & 5.01 & 10.62 \\
\hline 56 & E & $\begin{array}{r}\text { Jun-30 } \\
\text { May- }\end{array}$ & 1146 & 1 & 105 & A & M & $\mathrm{N}$ & 70 & 144.9 & $0.81 \%$ & 22 & 5 & 73.47 & 1.90 & 8.61 \\
\hline 57 & E & 30 & 1500 & 4 & 120 & A & M & $\mathrm{Y}$ & 72 & 154.33 & $6.33 \%$ & 92 & 1 & 78.11 & 7.70 & 15.19 \\
\hline 58 & $\mathrm{~F}$ & Jul-05 & 1413 & 1 & 76 & $J$ & M & $\mathrm{N}$ & 190 & 115.54 & $11.36 \%$ & 114 & 1 & 71.33 & 14.19 & 18.81 \\
\hline 59 & $\mathrm{~F}$ & Jul-06 & 1508 & 1 & 72 & J & $\mathrm{F}$ & $\mathrm{Y}$ & 174 & 92.85 & $5.15 \%$ & 102 & 1 & 92 & 9.43 & 23.40 \\
\hline 60 & F & Jul-08 & 1601 & 4 & 90 & J & M & $\mathrm{N}$ & 373 & 99.94 & $12.11 \%$ & 244 & 0 & 68 & 12.18 & 26.73 \\
\hline 61 & $\mathrm{~F}$ & Jul-13 & 1249 & 1 & 90 & $\mathrm{~J}$ & M & $\mathrm{Y}$ & 156 & 99.77 & $17.14 \%$ & 178 & 3 & 70.55 & 15.43 & 33.53 \\
\hline 62 & $\mathrm{~F}$ & Jul-20 & 1321 & 2 & 92 & A & M & $\mathrm{N}$ & 167 & 129.12 & $9.13 \%$ & 258 & 0 & 47.86 & 6.17 & 19.00 \\
\hline 63 & e & Jun- 02 & 1645 & 1 & 108 & A & M & $\mathrm{N}$ & 276 & 21.88 & $2 *$ & 140 & 0 & * & $2 *$ & $*$ \\
\hline 64 & $\mathrm{~F}$ & Jun-14 & 1802 & 5 & 115 & A & F & $\mathrm{N}$ & 143 & 126.55 & $7.45 \%$ & 172 & 9 & 78.36 & 15.16 & 25.60 \\
\hline 65 & $\mathrm{~F}$ & Jun-21 & 1554 & 5 & 70 & $\mathrm{~J}$ & M & $\mathrm{Y}$ & 227 & 111.26 & $8.84 \%$ & 172 & 2 & 67.08 & 0.00 & 14.25 \\
\hline 66 & $\mathrm{~F}$ & $\begin{array}{c}\text { Jun-27 } \\
\text { May- }\end{array}$ & 1635 & 5 & 105 & A & M & $\mathrm{Y}$ & 245 & 167 & $10.97 \%$ & 82 & 1 & 81.27 & 2.10 & 10.35 \\
\hline 67 & $\mathrm{~F}$ & $\begin{array}{r}11 \\
\text { May- }\end{array}$ & 1422 & 1 & 102 & A & M & $\mathrm{N}$ & 151 & 156.14 & $1.05 \%$ & 112 & 3 & 65.9 & 12.42 & 44.96 \\
\hline 68 & $\mathrm{~F}$ & 30 & 1716 & 4 & 110 & A & M & $\mathrm{Y}$ & 231 & 164.09 & $8.09 \%$ & 282 & 5 & 56.29 & 13.09 & 25.50 \\
\hline
\end{tabular}

*not calculated because pathway ended prematurely

**not calculated because of measurement error while tracing pathway

$* * *$ individual that crossed the road 
Appendix E. Pathway maps from each release. The italicized number to the right of the figure corresponds to the Animal ID in Appendix D. The light grey area represents the forest, the dark grey area represents the roadside verge and the black area represents a portion of the road edge starting at the verge/road edge. The entire width of the road surface is not represented in these maps. The grid cells are $2 \mathrm{~m}^{2}$. Pathways are represented by the irregular black line, unless the pathway ventured onto the road surface in which case the pathway is white. The release location is at the same coordinate at each site, $4 \mathrm{~m}$ from the forest/verge edge.
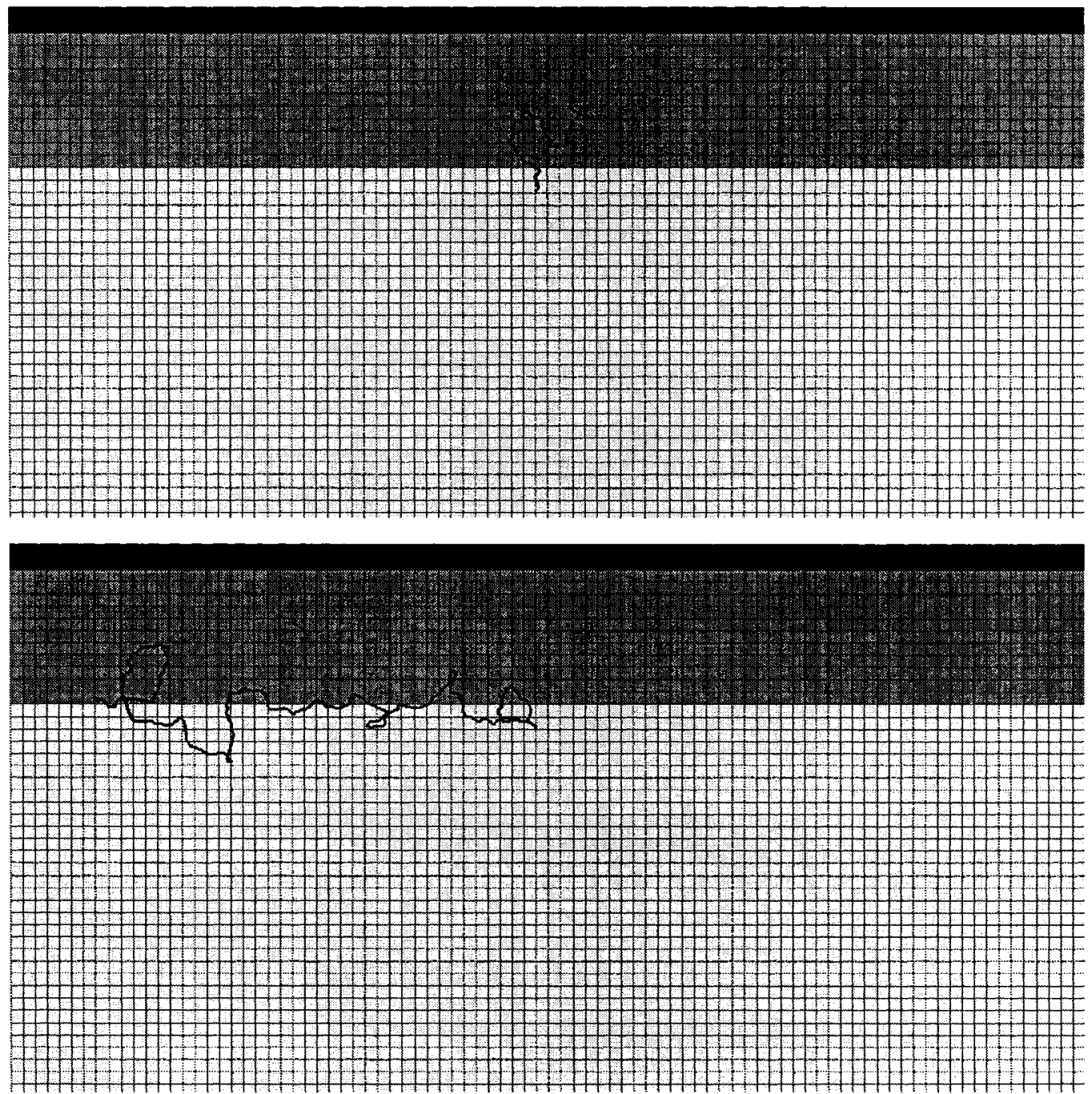



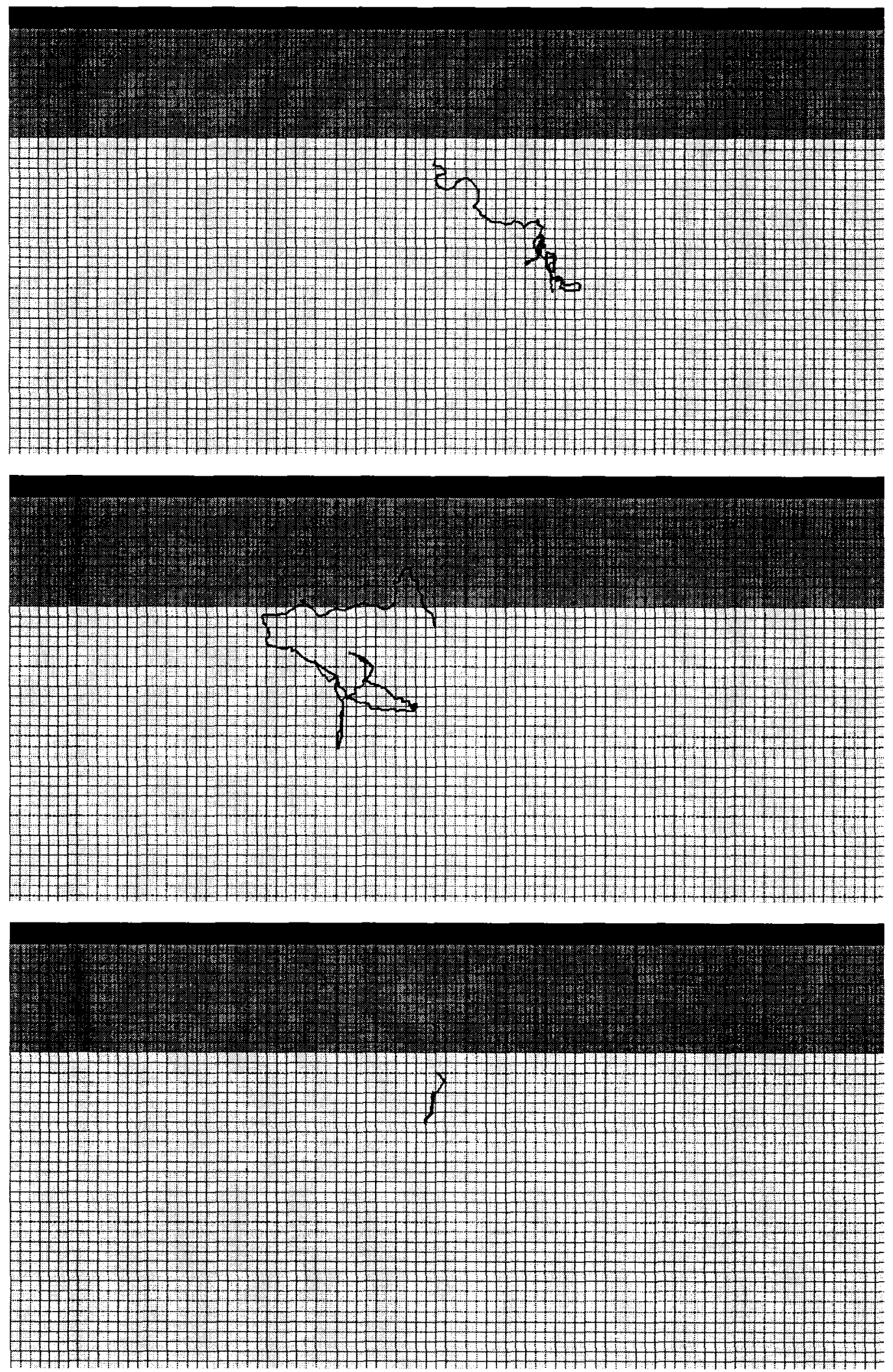

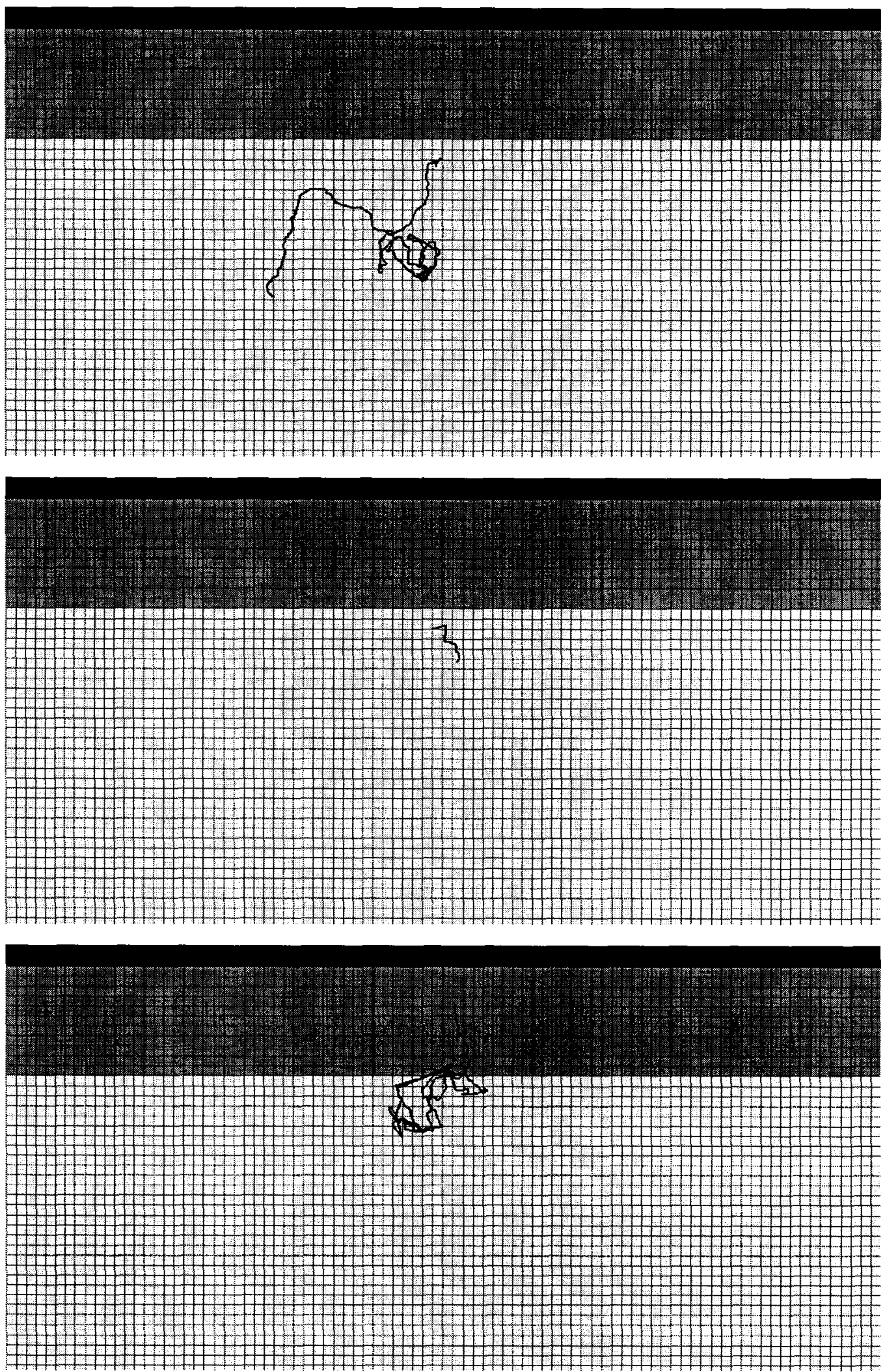

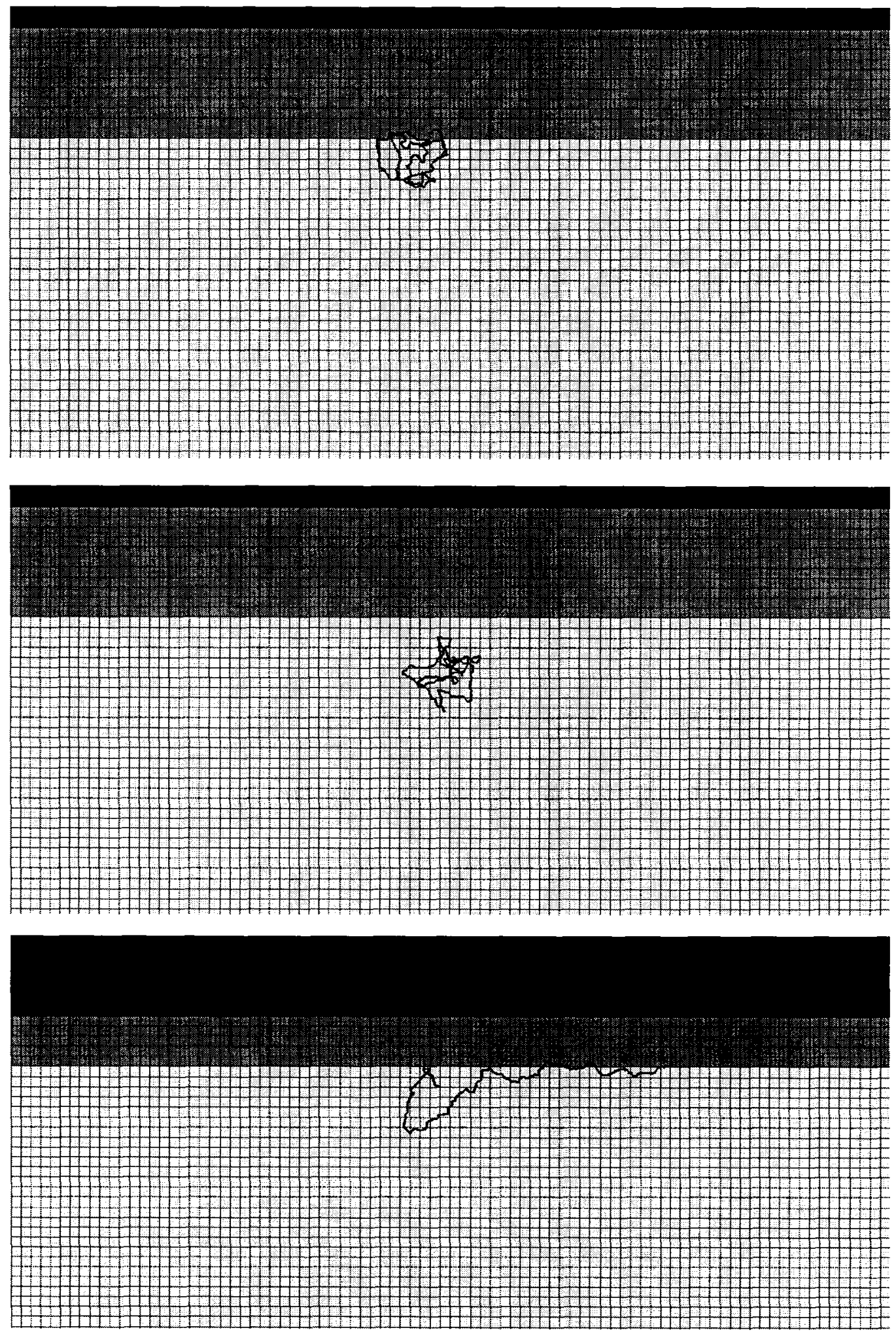



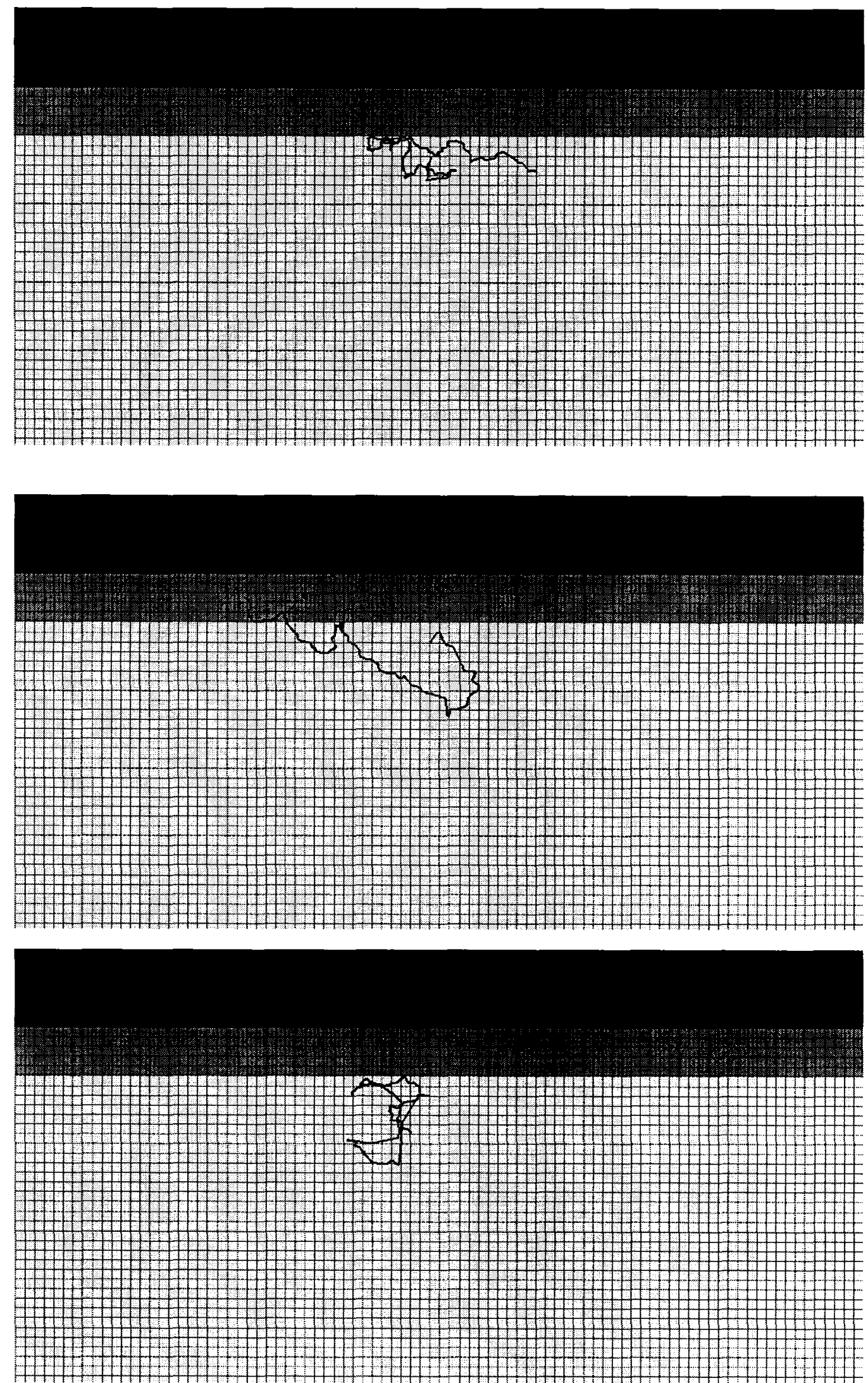

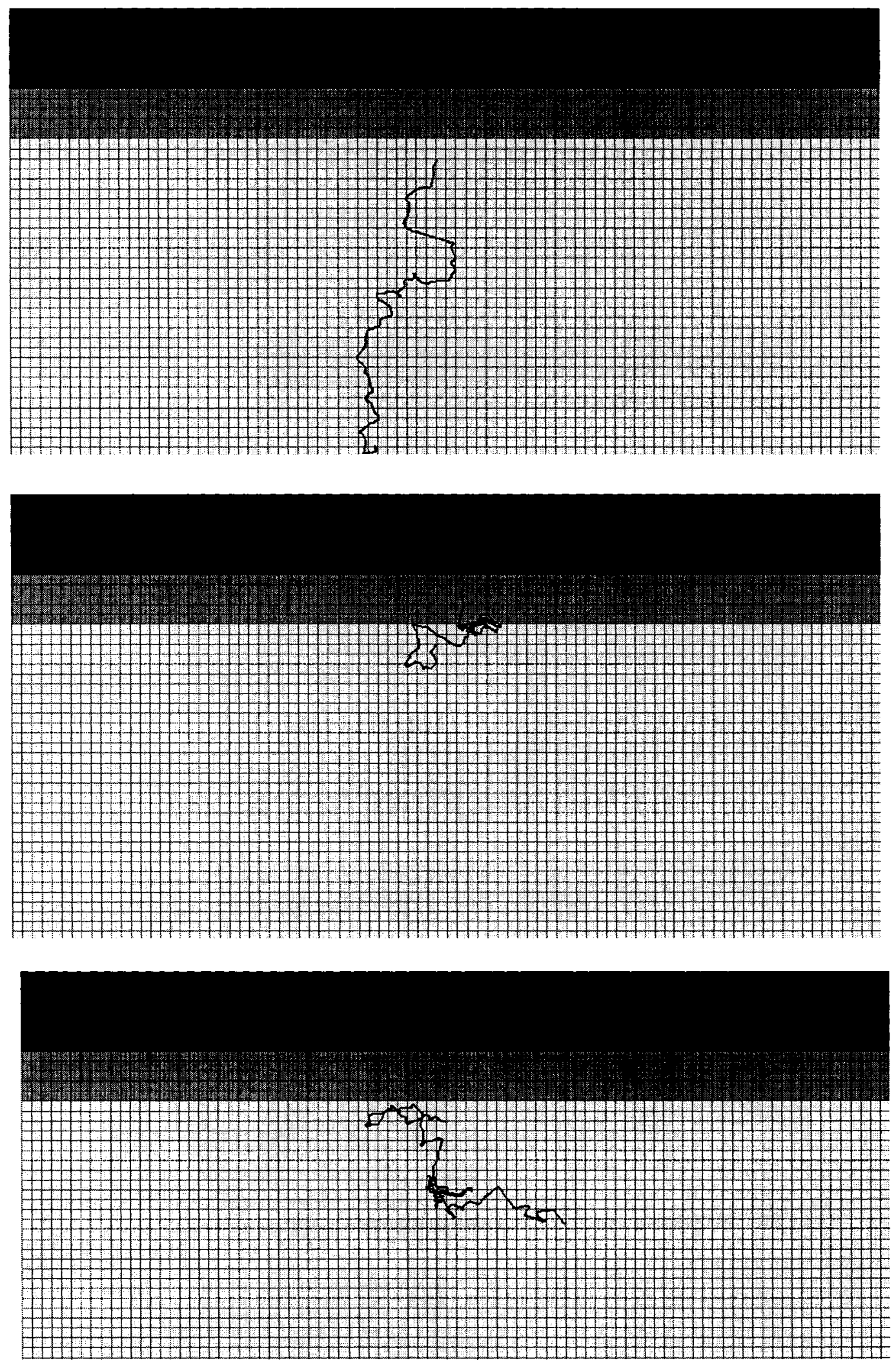

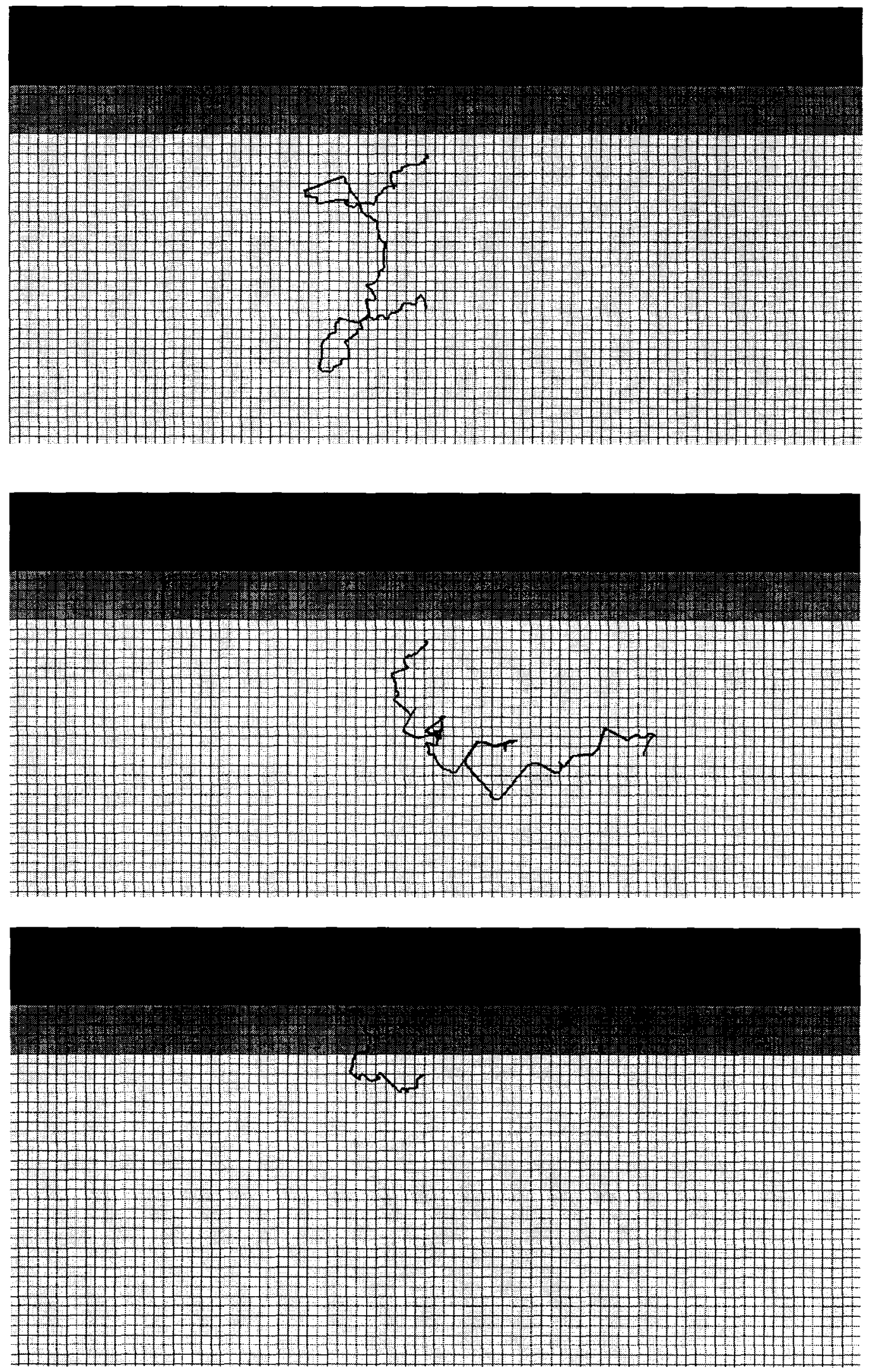

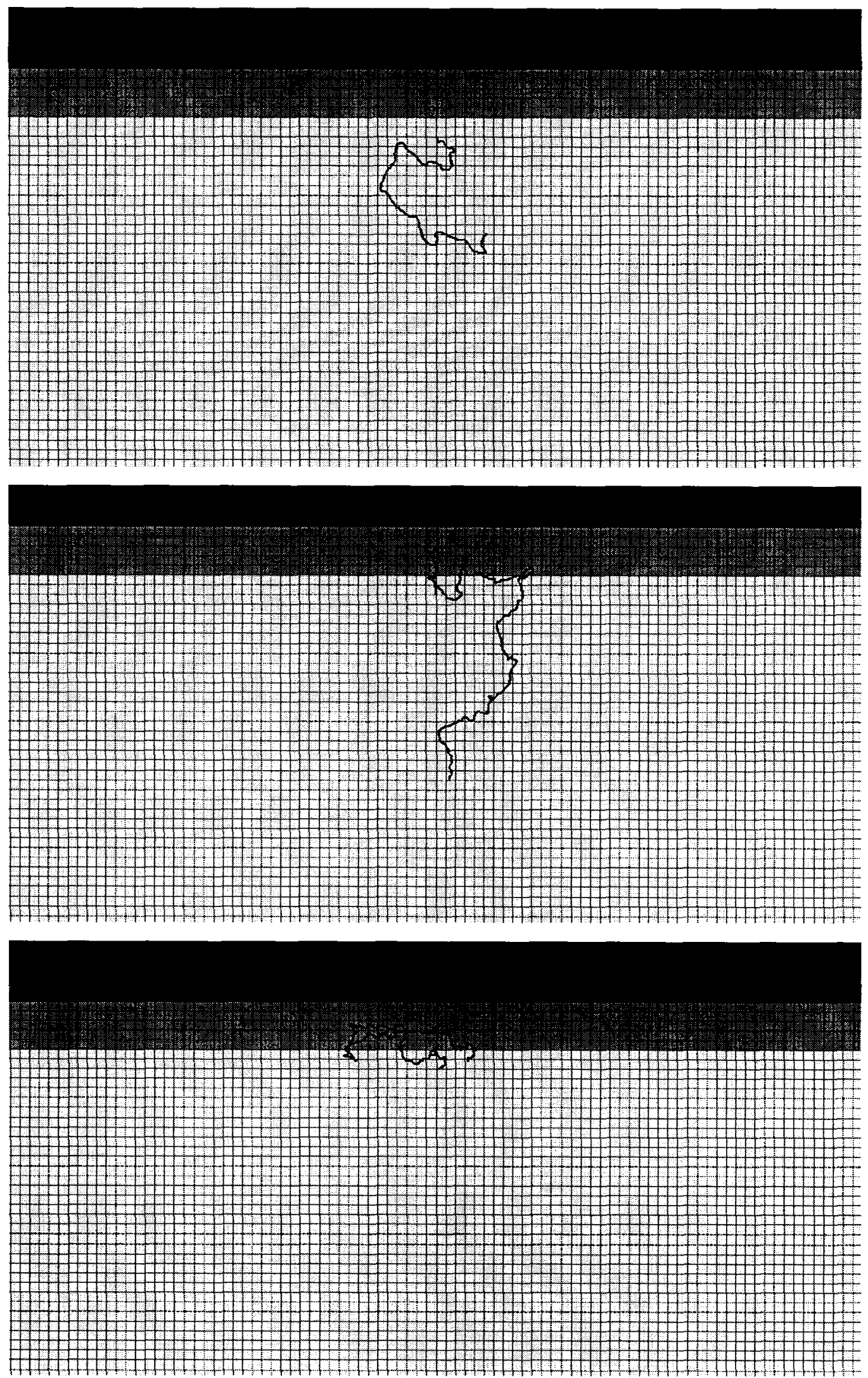

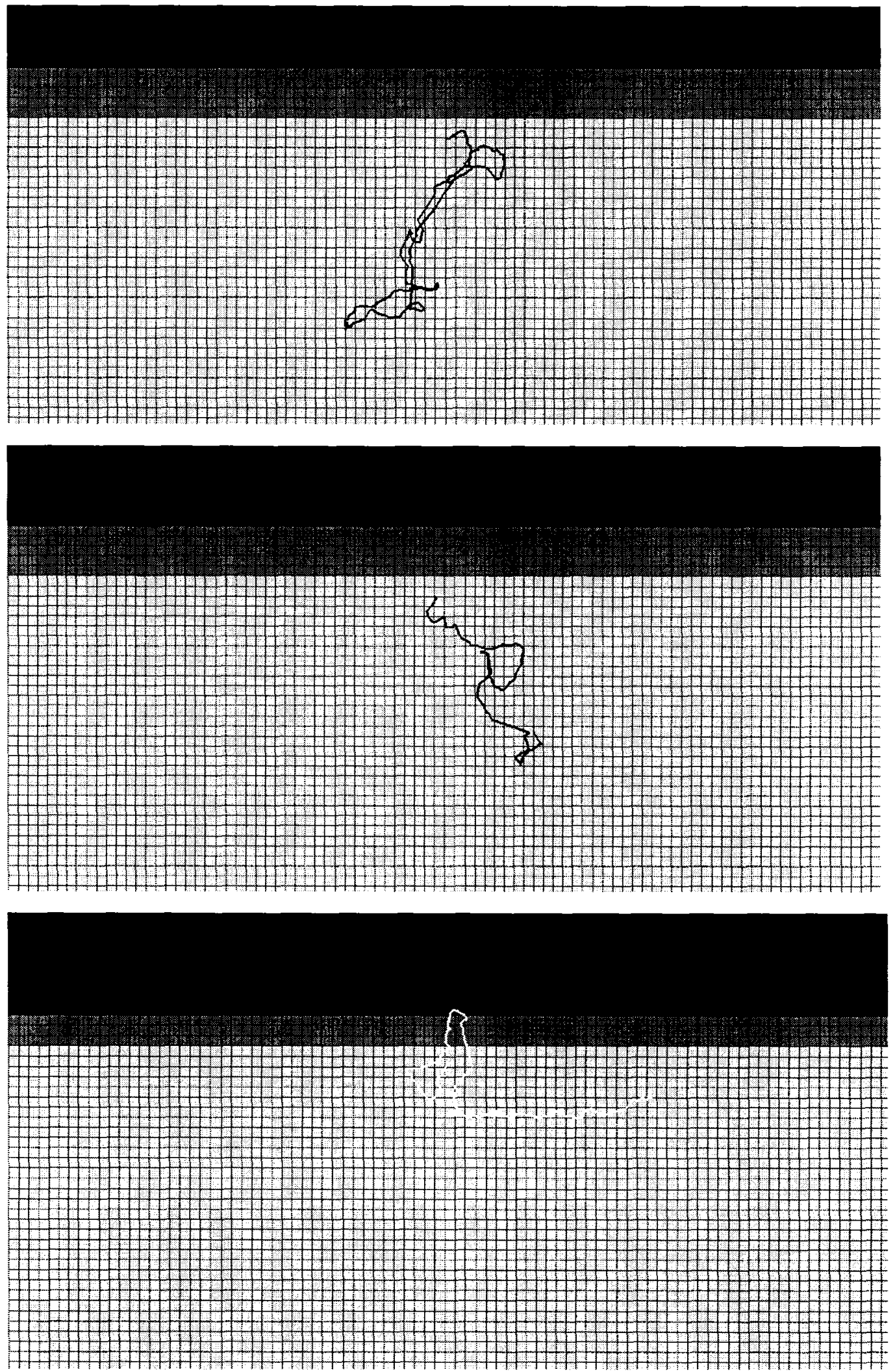

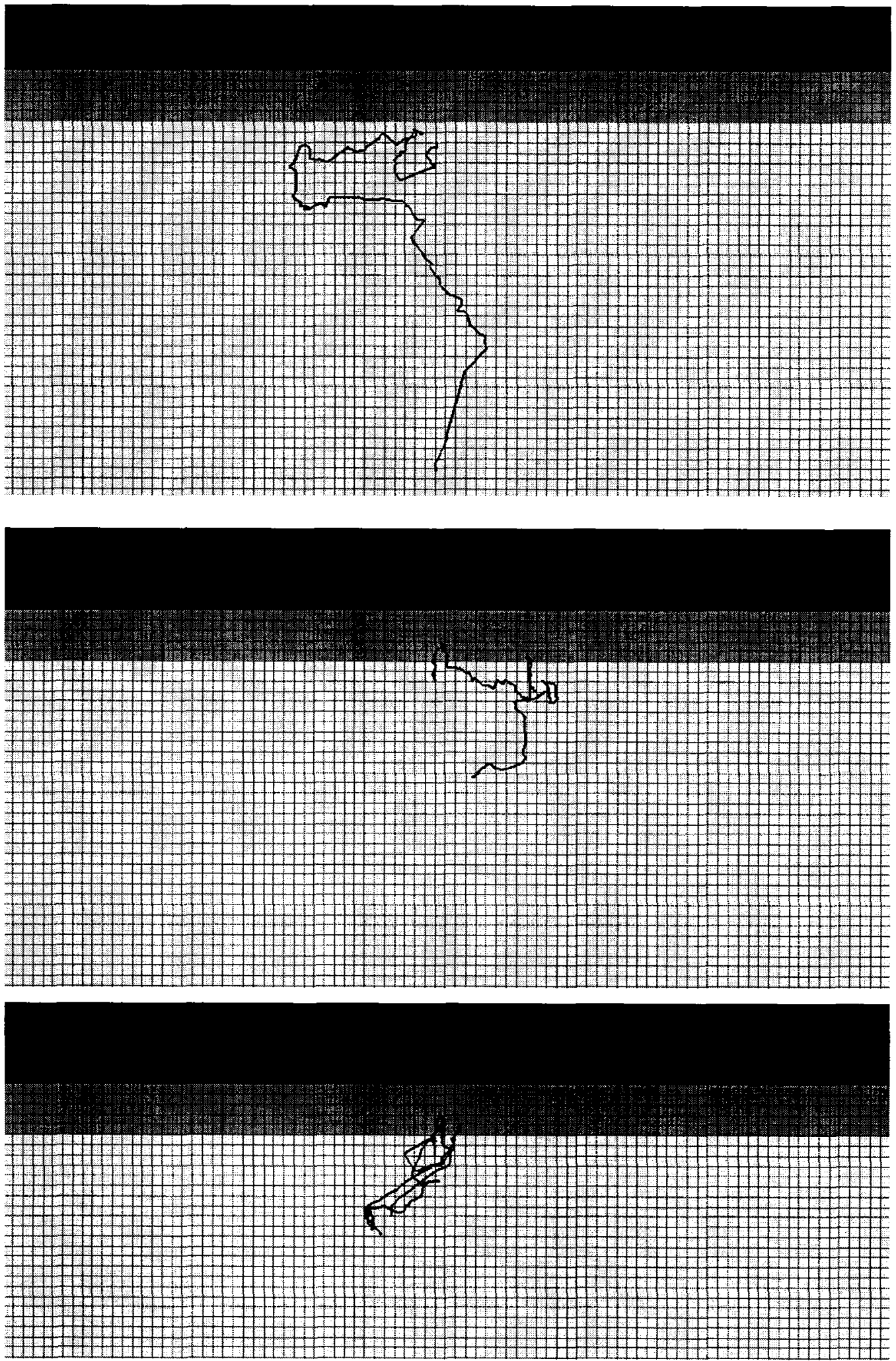



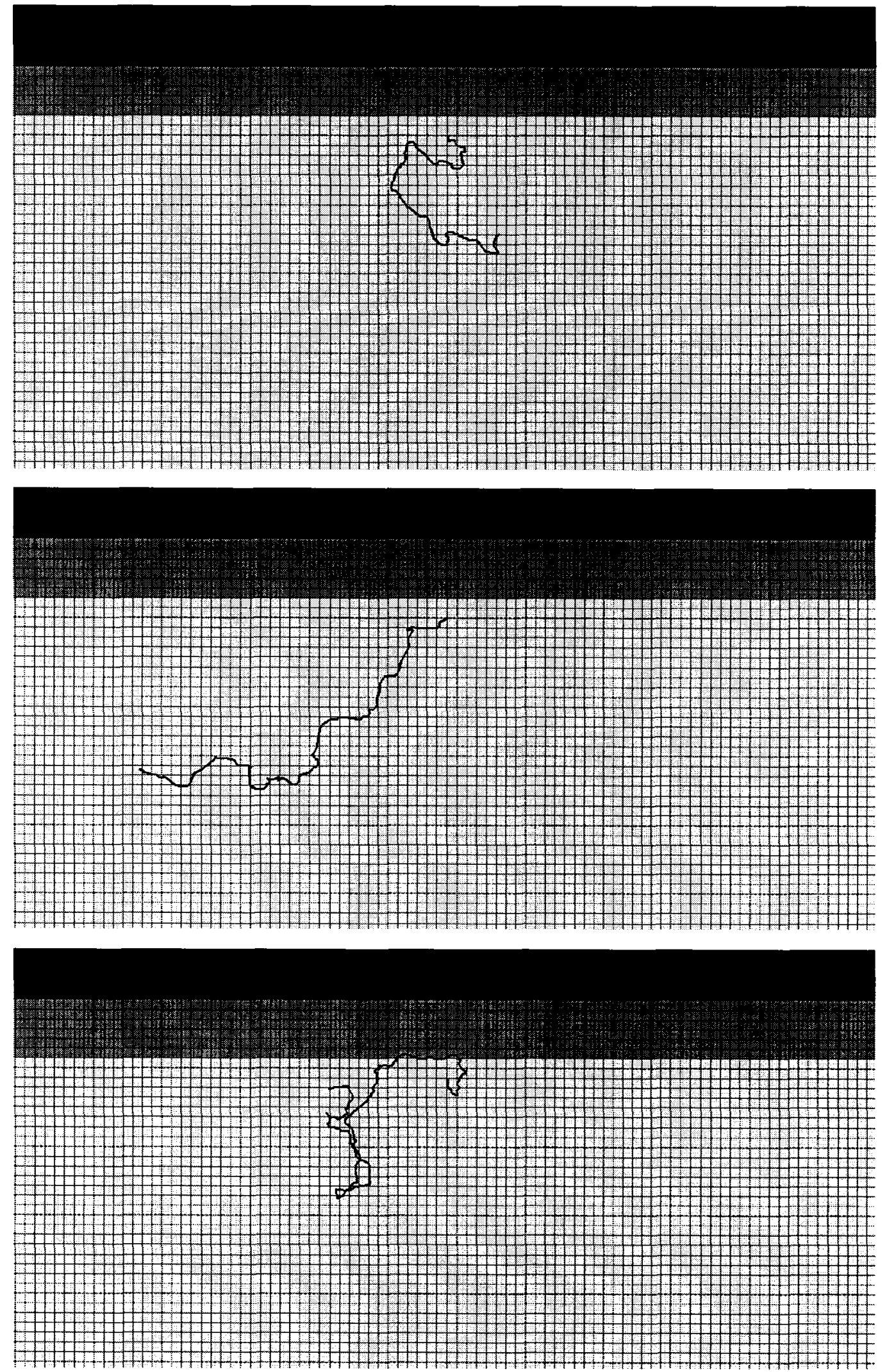

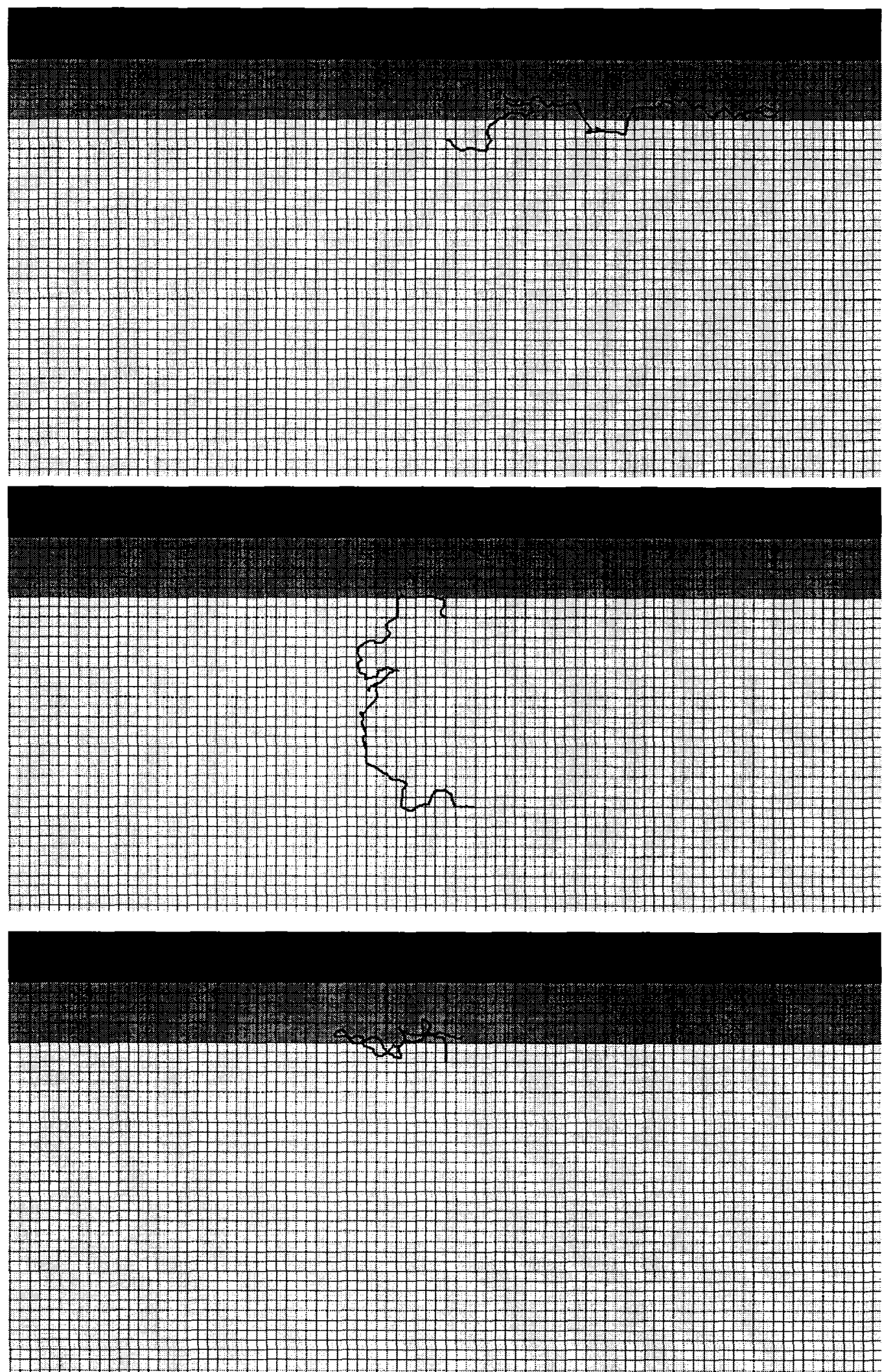

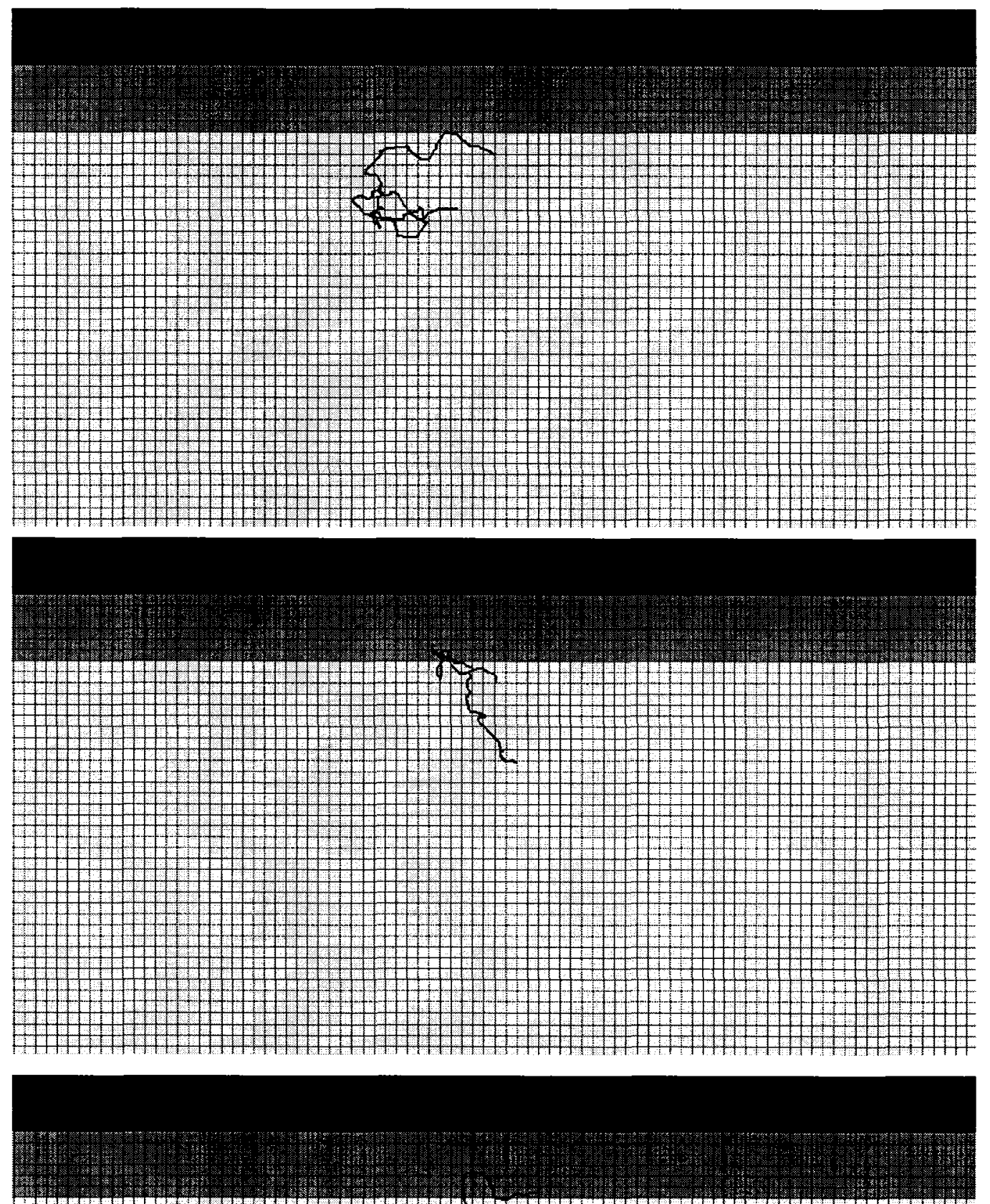

1. \begin{tabular}{|lllllll}
\hline & \\
\hline
\end{tabular} 

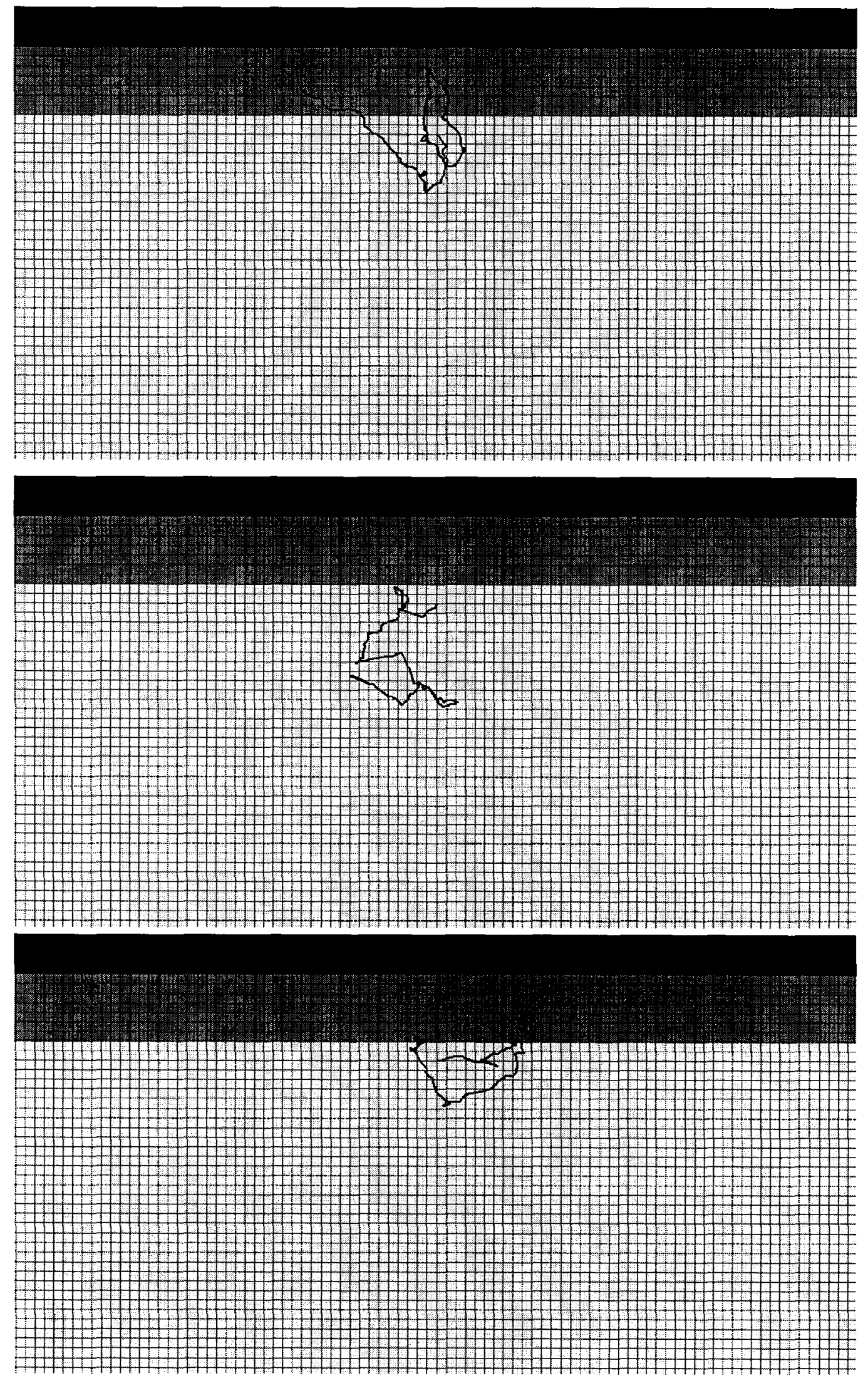

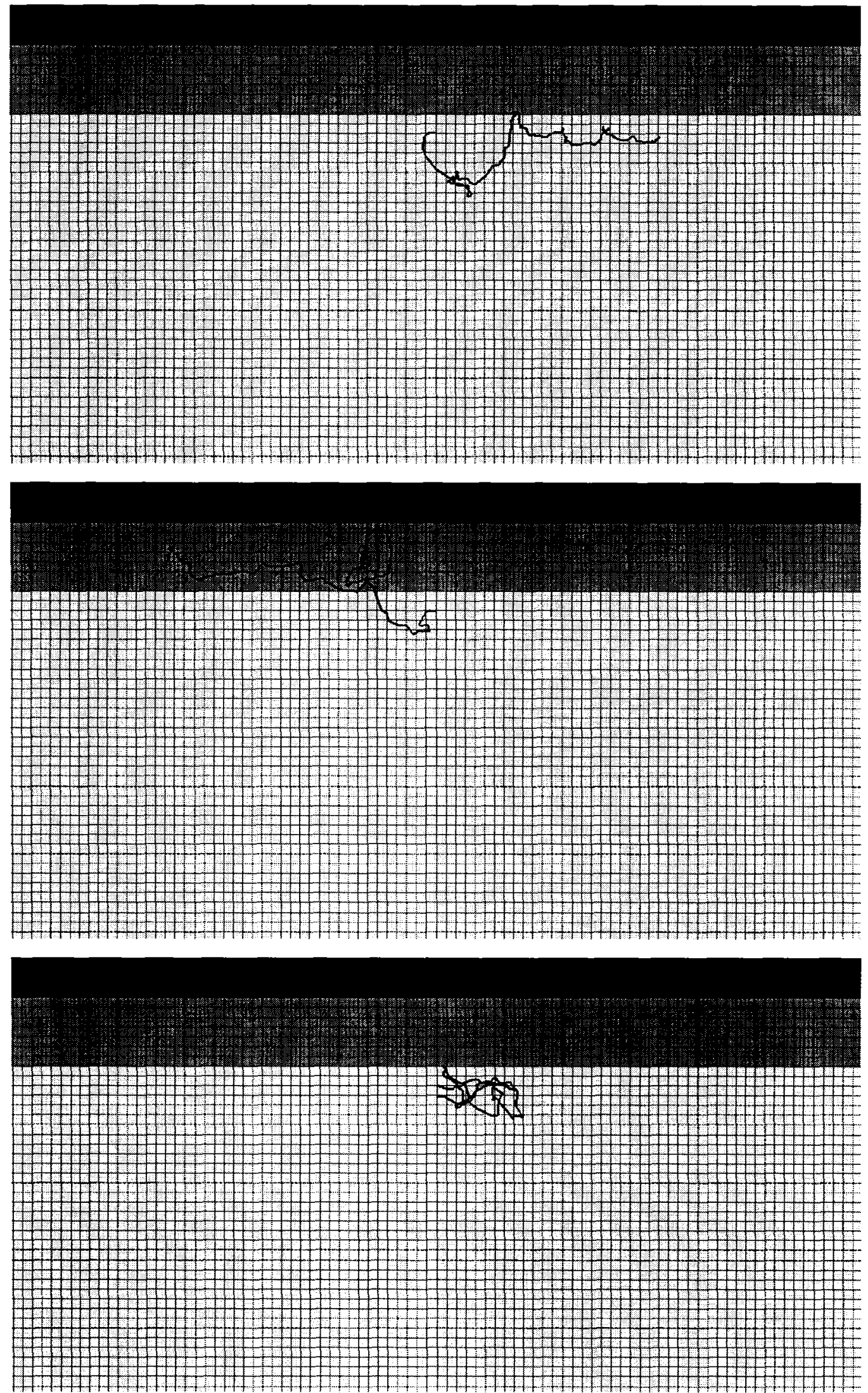

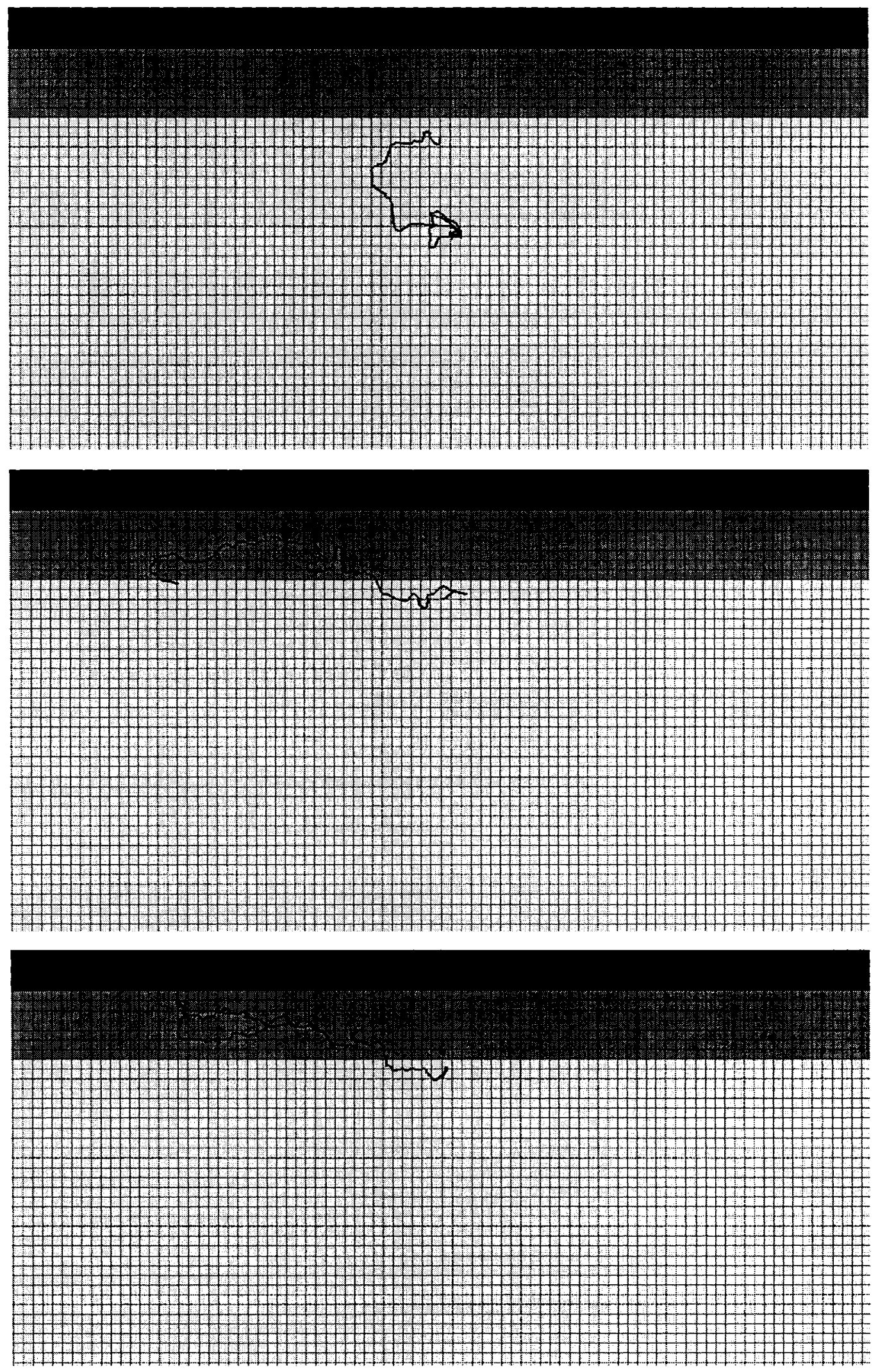





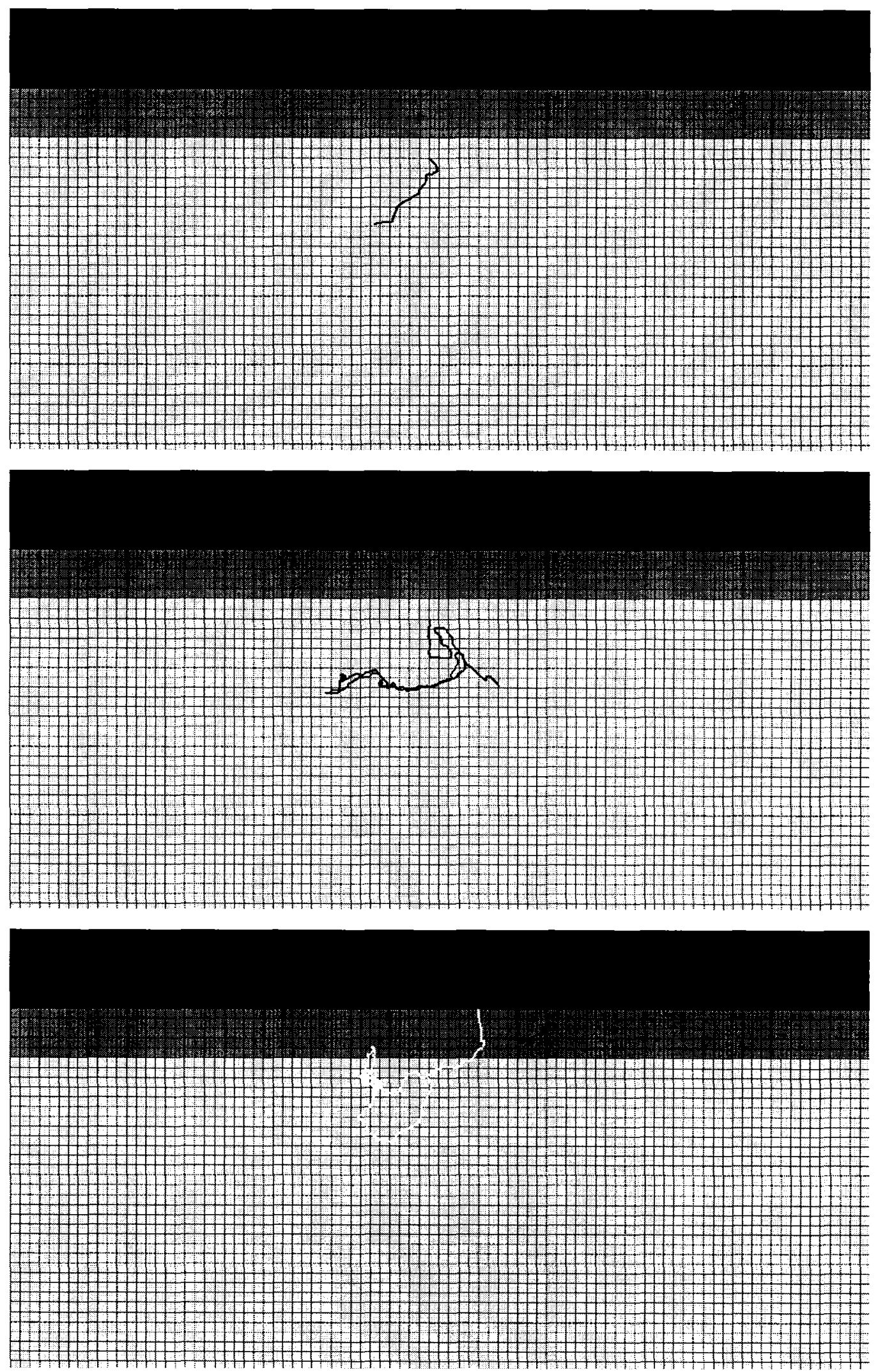

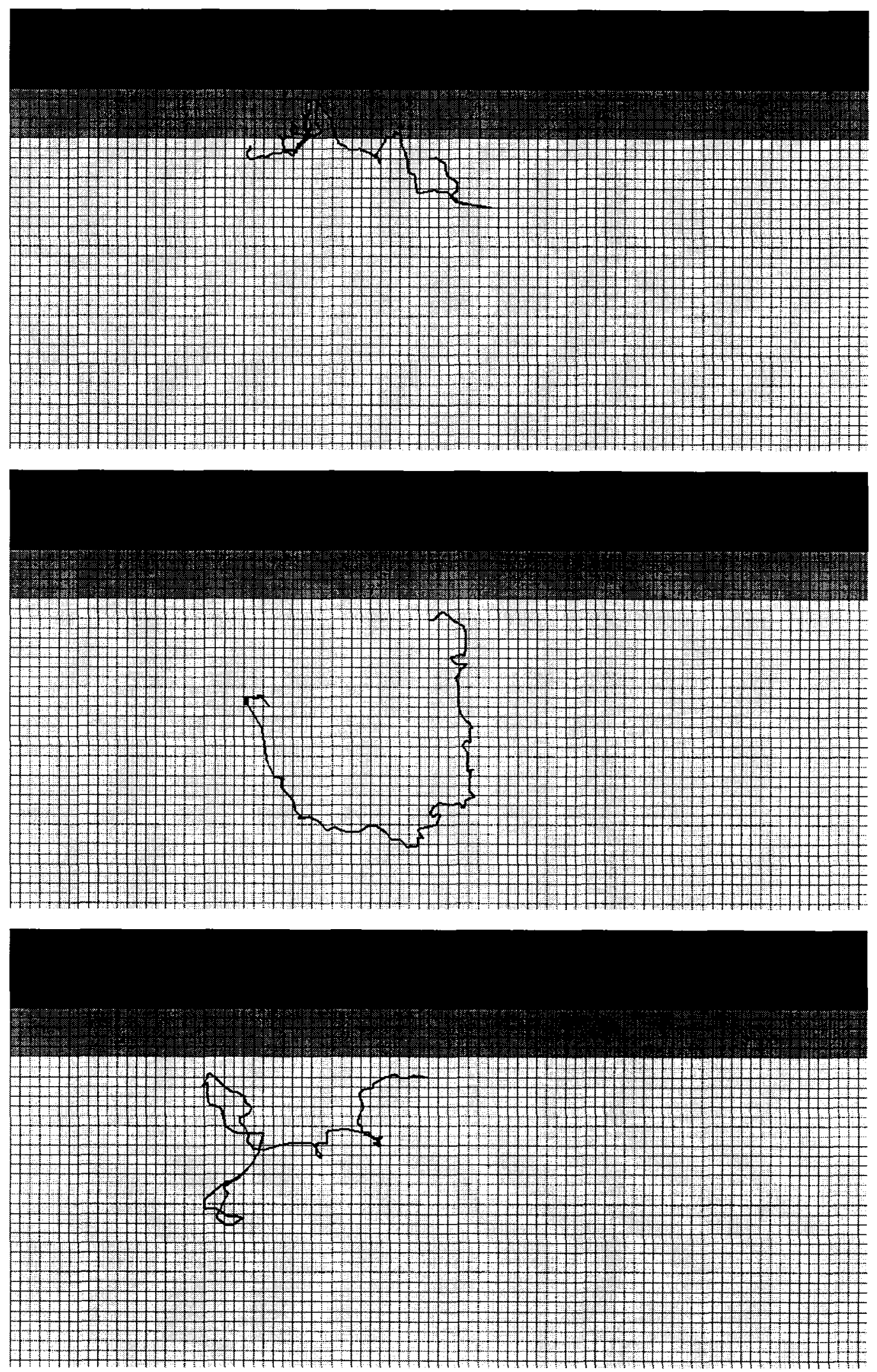